\title{
El ecoturismo como base para el desarrollo territorial sostenible en la Reserva de la Biosfera Sierra La Laguna (REBIOSLA), Baja California Sur, México
}

\section{Ecotourism as basis for dustainable territorial development in the Sierra La Laguna Biosphere Reserve, Baja California Sur, México}

\author{
Ismael Rodríguez Villalobos \\ Doctor en Ciencias Administrativas. Profesor - Investigador, \\ Universidad Autónoma de Baja California Sur, México. \\ Correo electrónico: ivilla@uabcs.mx \\ Angélica Montaño Armendáriz \\ Doctora en Ciencias Administrativas, Profesora- Investigadora, \\ Universidad Autónoma de Baja California Sur, México \\ Correo electrónico: amontano@uabcs.mx \\ Roberto González Sousa \\ Doctor en Ciencias Geográficas, Profesor Titular. Facultad de Geografía, \\ Universidad de La Habana, Cuba \\ Correo electrónico: rgsousa@geo.uh.cu
}

Resumen: este artículo pretende constituirse en una herramienta metodológica que desde el análisis de la importancia y pertinencia de impulsar un sistema territorial basado en la colaboración entre los actores sociales, propone estudiar las posibilidades y potencialidades que pudieran contribuir a conformar y fortalecer un sistema productivo de base ecoturística en la Reserva de la Biosfera Sierra La Laguna, localizada al noroeste de la República Mexicana, en el extremo Sur del estado de Baja California Sur y decretada como Reserva de la Biosfera el 6 de junio de 1994. El territorio cuenta con una población de 431 personas distribuida en 83 ranchos y dedicada a actividades primarias de escaso valor agregado. En el contexto territorial, el producto ecoturístico en desarrollo debe ser valorado como el núcleo en torno al cual se constituye la cadena productiva del sistema y las estrategias para su desarrollo deben obedecer al manejo responsable de los recursos naturales y culturales, mediante el establecimiento de lineamientos de ordenamiento que orienten la toma de decisiones hacia el diseño de productos coherentes, desde lo ambiental, lo social y lo económico. Como aportes de la investigación se señalan la apropiada actualización y adaptación sobre bases científicas del desarrollo de la actividad turística a las condiciones específicas de la REBIOSLA; revelar los elementos que deben conformar las relaciones de actores en el desarrollo de un sistema productivo de base ecoturística como alternativa de desarrollo territorial sostenible, y privilegiar una opción para resolver la contradicción fundamental que se establece entre las relaciones de los diferentes actores del territorio en el desarrollo de un producto turístico sostenible.

Palabras clave: ecoturismo, producto ecoturístico, desarrollo sostenible
Abstract: this article aims to be a methodological tool that, from the analysis of the importance and relevance of promoting a territorial system based on collaboration 
EL ECOTURISMO COMO BASE PARA EL DESARROLLO TERRITORIAL SOSTENIBLE EN LA RESERVA DE LA BIOSFERA SIERRA LA LAGUNA (REBIOSLA), BAJA CALIFORNIA SUR, MÉXICO
Ismael Rodríguez Villalobos Angélica Montaño Armendáriz Roberto González Sousa among social actors, proposes to study the possibilities and potentialities that could contribute to shaping and strengthening a ecotourism - based productive system In the Sierra La Laguna Biosphere Reserve, located in the northwest of the Mexican Republic, in the extreme south of the state of Baja California Sur and declared a Biosphere Reserve on June 6, 1994. The territory has a population of 431 Distributed on 83 ranches and dedicated to primary activities of little added value. In the territorial context, the ecotourism product in development must be valued as the nucleus around which the system's productive chain is constituted and the strategies for its development must obey the responsible management of the natural and cultural resources, through the establishment of guidelines Of ordering that

Recibido: febrero 2017 guide the decision making towards the design of coherent products, from the environmental, the social and the economic. As contributions of the research indicate the appropriate updating and adaptation on scientific bases of the development of the tourist activity to the specific conditions of the REBIOSLA; to reveal the elements that must form the relationships of actors in the development of a ecotourismbased productive system as an alternative to sustainable territorial development, and to favor an option to resolve the fundamental contradiction that is established between the relations of the different actors of the territory in the development of a sustainable tourism product.

Keywords: ecotourism, ecotourism product, sustainable development

Aceptado: septiembre 2017

\section{Introducción}

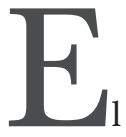

espacio turístico lo define Salinas (2003:77) “...como una formación socioespacial compuesta por dos tipos de espacios; los espacios materiales, construidos, ordenados y acondicionados, y los espacios inmateriales, imágenes salidas de las connotaciones mercantiles que la promoción turística crea a partir del espacio material". Vera et. al., 2011 (citado en López, 2014:15) lo "conceptualiza como el territorio donde se desarrollan los elementos que están relacionados con la actividad turística”, o sea, los que componen el sistema turístico, integrado por los recursos que pueden ser puestos en valor formando productos turísticos, las infraestructuras de acceso y apoyo, los alojamientos y el espacio de las actividades (López, 2014). Se diferencian estos espacios según sus atributos naturales e histórico-culturales, y los productos creados y mercantilizados que conducen a unos rasgos distintivos que les diferencian y que conforman el fenómeno turístico.

Para los entornos rurales, generalmente distantes de los territorios de mayor dinamismo económico y que se encuentran entre los más desfavorecidos, donde frecuentemente están presentes graves problemáticas demográficas y socioeconómicas, el turismo se presenta en la actualidad como un fenómeno estructural, además como un instrumento para su dinamización económica. Salinas (ob. cit., 76) se refiere al espacio turístico como un espacio productivo y destaca como cada forma de producción organiza el espacio según sus propias necesidades, lo que modifica su estructura. En estos escenarios se ha detectado la presencia de nuevos segmentos de demanda en las distintas modalidades de turismo que reportan una tendencia creciente, vinculados a 
la autenticidad y el valor de la riqueza patrimonial que ellos atesoran. Esta tendencia hace de la revalorización de los recursos locales, el marco propicio para el desarrollo de proyectos e iniciativas empresariales, donde el trabajo en red a partir del establecimiento de relaciones actorales es fundamental para conseguir la cohesión territorial, promover el protagonismo de los actores locales y su identificación con el lugar.

Avanzar en esta dirección y revertir la situación en los espacios rurales significa que las ayudas de gobierno, de organizaciones no gubernamentales, de la empresa privada y de otros actores con posibilidades de intervenir y apoyar cambios en su estructura económica, deben dirigirse a potenciar las asociaciones y el desarrollo de actividades, el alojamiento, la valorización del patrimonio, favoreciendo estas actuaciones la coherencia social, ambiental y funcional en estos espacios y su desarrollo sostenible.

Dado que los recursos naturales e histórico-culturales se constituyen en los de mayor importancia y relevancia en los espacios rurales, resulta necesario un planteamiento sistémico cuyo objetivo sea incidir en el marco de la nueva multifuncionalidad del medio rural con desarrollos sostenibles, es decir, desarrollo socioeconómico, manteniendo los valores patrimoniales y medioambientales (Sectur, 2010; López, 2014).

Muchos son los esfuerzos que en materia científica se realizan para lograr este objetivo. El desarrollo del turismo en armonía con la naturaleza y las culturas locales, y el ecoturismo como una de sus modalidades, es una oportunidad para el progreso armónico territorial, a partir de las relaciones de actores concertadas y la valorización de sus riquezas patrimoniales. Ello implica un procedimiento enfocado hacia la integración de las relaciones de los distintos actores como una herramienta a utilizar para el diseño de productos ecoturísticos en Parques Nacionales o áreas conservadas y la definición del ecoturismo desde la integración y las relaciones socioterritoriales fundamentales que lo caracterizan. Es importante destacar que el turismo en áreas protegidas representa una parte importante de la economía de muchos países y regiones, y esta tendencia va en aumento (Eagles et al., 2002).

Este artículo pretende constituirse en una herramienta metodológica que desde el análisis de la importancia y pertinencia de impulsar un sistema territorial basado en la colaboración entre los actores sociales que tienen que ver con la actividad turística, propone analizar las posibilidades y potencialidades que pudieran contribuir a conformar y fortalecer un sistema productivo de base turística en la Reserva de la Biosfera Sierra La Laguna (REBIOSLA). A su vez, representa una contribución a la literatura existente en esta área del conocimiento, donde se valora la adecuación del desarrollo del ecoturismo a las pautas del desarrollo sostenible, a través de un procedimiento que articula las relaciones de actores en el territorio, con un enfoque sistémico, que integra los procesos de la realidad espacial a la perspectiva de un producto ecoturístico.

\section{Fundamentación teórica}

Las características que hoy exhibe la economía sudcaliforniana tiene como fuerza motriz el crecimiento de la actividad terciaria, sustentada en sus recursos patrimoniales, tanto naturales e histórico culturales, y que posibilitan el desarrollo de un producto turístico de reconocimiento internacional De ahí, que el análisis e identificación de las actividades productivas con capacidad para fortalecer el tejido de relaciones sectoriales no pueda reducirse al universo de los sectores productivos de base primaria o industrial, 
EL ECOTURISMO COMO BASE PARA EL DESARROLLO TERRITORIAL SOSTENIBLE EN LA RESERVA DE LA BIOSFERA SIERRA LA LAGUNA (REBIOSLA), BAJA CALIFORNIA SUR, MÉXICO
Ismael Rodríguez Villalobos Angélica Montaño Armendáriz Roberto González Sousa

como es lo común. Negar que el turismo actúa como modelador de las escasas relaciones intersectoriales que hoy existen en el territorio y que debe estar llamado a fomentar el entramado de las redes económicas en el territorio de la península, es negar la realidad del acontecer económico sudcaliforniano de las últimas cinco décadas, su situación geográfica con respecto al principal mercado emisor de turistas y su proyección a futuro (Suárez et al., 2016).

Desde este punto de vista adquiere especial relevancia identificar las actividades económicas que cumplan con determinadas características sectoriales y territoriales que, eventualmente, puedan ser sujetos de políticas públicas para desarrollar sistemas productivos locales y fortalecer el tejido productivo en Baja California Sur, sus municipios y espacios naturales comprendidos en distintas categorías de manejo, adquiere especial relevancia. Esto implica buscar como objetivo a corto plazo, una organización territorial de las actividades económicas integrada en redes, donde se reconozca la importancia de los territorios, de los lugares y sus potencialidades, formando sistemas territoriales productivos locales competitivos de base turística en la REBIOSLA, un objetivo a alcanzar a corto plazo.

Jiménez $(2010: 15,24)$ destaca que "La promoción del turismo en el mundo ha de verse sobre todo desde la perspectiva de su globalidad. Es el turismo una de las actividades económicas donde los fenómenos de la globalización y de la competitividad planetaria se observan más claramente en el ámbito transnacional...". Más adelante señala: "La globalidad está hecha de imágenes insertadas como chips en los cerebros de las personas que habitan por ahora en este mundo pero también está conformada por intereses que adquieren y busca insertar esos chips - u otros- frecuentemente sólo para sustituir el objeto de deseo pero con la misma finalidad económica”. No es posible obviar esta característica del turismo en la planificación y gestión de su desarrollo.

La cristalización de sistemas productivos locales de base turística en la reserva tiene como factores formadores o impulsores de este proceso, el entorno social y la herencia cultural que atesora el territorio, la cual debe constituirse en soporte de la cohesión social y el establecimiento de relaciones de colaboración entre los actores locales. Contribuye a este objetivo, la existencia de unos recursos humanos con conocimiento del entorno y fuente, ya en la actualidad, de iniciativas micro empresariales de carácter endógeno y una demanda creciente por modalidades de turismo que revalorizan los recursos locales y pueden favorecer el desarrollo de redes de Pymes especializadas en estos destinos y nuevas oportunidades de empleo.

El turismo como concepto ha cambiado, de un turismo de masas a un turismo que busca destinos turísticos con altos valores ecológicos, ambientales y sostenibles. Esta variación responde a un cambio en la mentalidad del hombre, y a su preocupación por temas ambientales, su propia supervivencia y la de su hábitat, lo que representa avanzar desde una perspectiva puramente económica y enajenante en el desarrollo del turismo, a concebirlo como una práctica que reivindica el sentido del lugar. Todo ello ha generado a nivel mundial, una tendencia a la práctica del turismo de naturaleza, modalidad que absorbe en la actualidad una parte de los viajeros, que desean pasar un tiempo de ocio en áreas conservadas con valores históricos, culturales y en contacto con las comunidades rurales, sus experiencias, creencias y modos de actuación.

El turismo de naturaleza, “(...) es un producto genérico, es decir una sombrilla de 
productos y ofertas que tienen a la naturaleza, o a partes de esta, como atributo motivador del viaje (...)" (Medina et al., 2010:84). Según estos autores, es una conceptualización amplia que identifica a tres productos principales: ecoturismo, agroturismo y turismo de aventuras, basados en el acercamiento y disfrute del patrimonio natural y cultural de un espacio, íntimamente asociados al interés del visitante por el contacto con el medio natural y el conocimiento de las culturas locales. Las formas asociadas al turismo de naturaleza, se realizan en espacios naturales en mayor o menor medida conservados, una de las modalidades más consolidadas, es el ecoturismo.

La Organización Mundial del Turismo (OMT) define al turismo de naturaleza como toda forma de turismo basado en la naturaleza, en la que la motivación principal de los turistas sea la observación y apreciación de la naturaleza o de las culturas. Al referirse al ecoturismo declara que es más amplio y se realiza en zonas naturales relativamente intactas, fundamentalmente con el objetivo de admirarlas y aprender más acerca de ellas. El ecoturismo supone que el turoperador y los visitantes asuman cierta responsabilidad con respecto al destino, reduciendo o evitando los impactos negativos sobre las zonas visitadas. La OMT destaca que la práctica del ecoturismo debería contribuir a la protección de las zonas naturales, y generar beneficios económicos para las comunidades locales, además de incrementa la concienciación sobre la conservación tanto en los habitantes de la zonas como en los turistas (OMT, 2002).

La diferencia fundamental con otros productos o modalidades turísticas (Martínez, 2001) en espacios naturales, se centra en que su motivación principal es el contacto con la naturaleza que en muchos momentos se lleva a cabo en áreas incluidas en alguna categoría de conservación. Resulta importante valorar la necesidad de armonizar la actuación de los productos que conforman el ecoturismo en la proyección del espacio estudiado, en este caso, la REBIOSLA y sus regiones. El ecoturismo, por sus principios, sustenta un proceso de mejora social que satisface las necesidades y los valores de todos los grupos interesados, al mantener al mismo tiempo, las opciones futuras y aprovechar de forma racional los recursos naturales. Según Pérez (2004), puede significar para los pobladores de las áreas naturales, por ejemplo, la creación de nuevos puestos de trabajo, aumento en los ingresos y un nuevo impulso a la artesanía y otras producciones locales.

Como modalidad de desarrollo del turismo, permite al visitante una mejor comprensión de las formas de uso de los espacios rurales, siendo considerado una forma de desarrollo de turismo sostenible en estas áreas, constituyendo a su vez un proceso de transculturación a través del cual se produce un intercambio de costumbres, lenguajes, artes, gastronomía, estilos productivos entre los turistas y la población local, con un estilo de vida ecológico; siempre respetando y cuidando el medioambiente y las tradiciones de la localidad. A su vez, representa una tendencia dirigida al desarrollo de la economía familiar, de pequeñas y medianas empresas que sustituyen a las grandes compañías, pues el ecoturismo requiere de una inversión menor de capital que otras empresas del sector; de ahí que resulte una buena opción en regiones rurales generalmente marginadas de las principales dinámicas económicas globales (Pérez, 2004).

El ecoturismo es una de las modalidades más responsables con el entorno natural y la integridad cultural, promueve la conservación del área y contribuye, además, al mejoramiento de la calidad de vida, tanto de visitantes como de la población local. Es 
EL ECOTURISMO COMO BASE PARA EL DESARROLLO TERRITORIAL SOSTENIBLE EN LA RESERVA DE LA BIOSFERA SIERRA LA LAGUNA (REBIOSLA), BAJA CALIFORNIA SUR, MÉXICO
Ismael Rodríguez Villalobos Angélica Montaño Armendáriz Roberto González Sousa

indudable, que para el éxito del ecoturismo, en especial en áreas protegidas, deben desarrollarse procedimientos que permitan tomar decisiones razonadas, lógicas y defendibles, enfocados a la interdisciplinariedad, con un enfoque integral y sistémico, que responda a las particularidades de cada territorio y país, basadas en el adecuado ordenamiento y planificación, en las reglamentaciones de uso y en el control efectivo del número de visitantes.

En el contexto territorial, el ecoturismo como expresión tangible del conjunto de relaciones debe ser valorado como el núcleo en torno al cual se constituye la cadena productiva del sistema. Por tanto, las estrategias de desarrollo ecoturístico en los territorios deben obedecer al manejo responsable de los recursos naturales y culturales, mediante el establecimiento de lineamientos de ordenamiento que orienten la toma de decisiones hacia el diseño de productos coherentes, desde lo ambiental, lo social y lo económico, lo cual debe apoyarse en el diseño de un plan de marketing para la promoción y un mejor funcionamiento de las actividades ecoturísticas en el territorio.

Muchos son los países que han apostado a desarrollar el ecoturismo en Parques Nacionales. México es uno de ellos, enfocando el desarrollo del ecoturismo como vía de conciliación entre la práctica turística y la conservación de espacios naturales con diferentes categorías de conservación. En este sentido, es de vital importancia propiciar un estilo de desarrollo turístico diferente, en cuanto a la concepción de producto ecoturístico, que permita aportar soluciones al desarrollo del turismo en espacios conservados, y aliviar los conflictos generados en territorios donde prevalecen varios actores con diferentes actividades económicas y a la vez, conseguir minimizar el deterioro ecológico, así como la pérdida de los recursos naturales renovables Jiménez (1998).

El ecoturismo debe convertirse en una herramienta útil para el desarrollo de las áreas protegidas. No se trata de un concepto con implicaciones exclusivamente económicas, sino que fomenta el rescate de tradiciones culturales y genera un nivel de relaciones entre sus actores, fortaleciendo los nexos en el territorio. Muchos son los autores y los grupos de trabajo que han abordado el estudio del ecoturismo desde las relaciones de actores: Chávez (1997) y la Red Mexicana de Ecoturismo (2009), señalan la importancia de la integración intersectorial e identifican el ecoturismo desde el propio desarrollo del proceso turístico, proponiendo la necesidad de incorporar la visión multidisciplinaria, que responda a la satisfacción de las necesidades sociales en función de un desarrollo sostenible.

Los criterios anteriores apoyan la necesidad de un desarrollo ecoturístico armónico, a través de una integración intersectorial y de los actores implicados con una visión multidisciplinaria. Una posible solución desde las relaciones de actores la propone Ceballos-Lascurain (1998, 2001), mediante la creación de Consejos Nacionales de Ecoturismo (CNEs) y de grupos análogos a nivel local que actúen bajo un conjunto de prioridades establecidas. En las Áreas Naturales Protegidas (ANP) de México, incluyendo por supuesto a la REBIOSLA, si bien cuentan con un espacio institucional denominado "El Consejo Asesor", entendido como un órgano de gobierno que opera como espacio de participación, vinculación y gobernanza para los diferentes actores que tienen que ver o están interesados con el manejo de la reserva en todos sus aspectos (ambiental, social y productivo), este opera más como un espacio de gobierno que de gobernanza y donde los actores comunitarios tienen un rol pasivo. 
De igual manera, la agenda de este Consejo está dominada por los temas ambientales y no se discuten temas que tengan que ver con las actividades productivas y mucho menos con la competitividad. Se requiere que el espacio institucional esté más cercano a las comunidades, permita la comunicación entre los actores locales para resolver problemas, conciliar conflictos, establecer mecanismos de colaboración productiva e integrar la competitividad productiva en su agenda y al objetivo de desarrollo local. La figura de ANP debiera de propiciar esquemas colaborativos y participativos entre los actores comunitarios, sociales, institucionales, académicos, etc. Las ANP necesitan del turismo y el turismo necesita de las ANP, relación siempre compleja que puede llegar a ser conflictiva, y que hace del turismo siempre un componente crítico que hay que tener en cuenta en la constitución y gestión de áreas protegidas (Eagles et al., 2002).

La práctica del turismo en la Reserva de la Biosfera Sierra La Laguna (REBIOSLA) requiere de cierta infraestructura de atención a los visitantes, que debe emplazarse con cautela porque puede romper completamente su armonía y afectar su patrimonio natural y cultural. Su diseño y funcionamiento debe reflejar sus valores patrimoniales (vida silvestre, paisajes, enclaves históricos, rasgos arquitectónicos, prácticas culturales, entre otras) y responder a la política de gestión de la Reserva.

Los autores consideran que para facilitar la interrelación sistémica entre los diferentes actores y el ecoturismo a nivel local, no basta solamente con la existencia de un Consejo Asesor Local, sino que dependerá de su actuación, prestándole una mayor atención a la sostenibilidad del territorio, desde la funcionalidad y jerarquización, el intercambio y diferenciación jerárquica de las variables externas: ambiental, económica, legal, social, cultural y política, expresadas mediante el ejercicio de poder y que inciden en las variables internas, representadas en el territorio por los actores locales. Estos, a su vez, presionan sobre los recursos, considerando que no todas las variables internas reciben y emiten materia, energía e información de igual manera, y se ven expresadas de la misma forma en las relaciones de actores. Si se maneja el área natural como un todo, pensado desde la sostenibilidad, corresponde gestionar desde la integración a todos los actores que intervienen en el área y su espacio de influencia, desde todas las dimensiones, para lo cual conformar y fortalecer un sistema productivo local de base turística constituye una tarea de primordial importancia.

En otras palabras, es necesario transformar al territorio de la REBIOSLA en un marco propicio para el desarrollo de micro y pequeñas empresas, integradas en sistemas productivos locales y cadenas de valor, en función de los valores patrimoniales y las características y expectativas de la población local, así como de las relaciones locales que en él se puedan tejer. Alcanzar un alto grado de competitividad territorial en este destino, implica afrontar la competencia de un mercado cada vez más exigente de productos prístinos, y garantizar al mismo tiempo, la viabilidad medioambiental, económica, social y cultural, aplicando lógicas de red y de articulación ínter territorial entre pymes, actores y comunidad locales.

Este proceder posibilita que la reserva incorpore valores añadidos, tales como: mayor grado de conservación, valor sistémico, mayor organización local, mayor desarrollo económico y financiero en función del progreso de las economías locales, mejor aplicación de las nuevas tecnologías en el manejo sostenible del área natural o protegida. Si el área natural se gestiona mediante un manejo ecoturístico con buenas y 
eficientes relaciones entre actores, sustentado en sistemas productivos locales de base turística, esto puede contribuir al desarrollo sostenible, a la creación de un producto que genere las vías de progreso de las comunidades anfitrionas y los actores participantes, a partir de sus propias condiciones y recursos, lo que les sitúa como centro de su propio desarrollo, y a superar las posibles contradicciones que surjan en el desarrollo del destino ecoturístico.

\section{Caracterización general del territorio de la Reserva de la Biosfera Sierra La Laguna}

La Reserva de la Biosfera Sierra La Laguna se localiza al noroeste de la República Mexicana, en el extremo Sur del estado de Baja California Sur. El área conocida como Sierra La Laguna se encuentra ubicada al Sur del municipio de La Paz y al Norte del municipio de Los Cabos. Su delimitación queda comprendida entre los paralelos $23^{\circ} 42^{\prime}$ y $23^{\circ} 20^{\prime}$ y los meridianos $109^{\circ} 46^{\prime}$ y $110^{\circ} 11^{\prime}$. Cuenta con una extensión territorial de 112,437 hectáreas, de ellas, 79,917 hectáreas corresponden a la zona de amortiguamiento. Fue decretada como Reserva de la Biosfera el 6 de junio de 1994 y se localiza en la parte sur del estado de Baja California Sur, constituyendo parte de un macizo montañoso, del que la Reserva, ocupa una extensión de aproximadamente 48 kilómetros de largo y un promedio de 20 kilómetros de ancho (CONANP, 2003) (Figura No. 1).

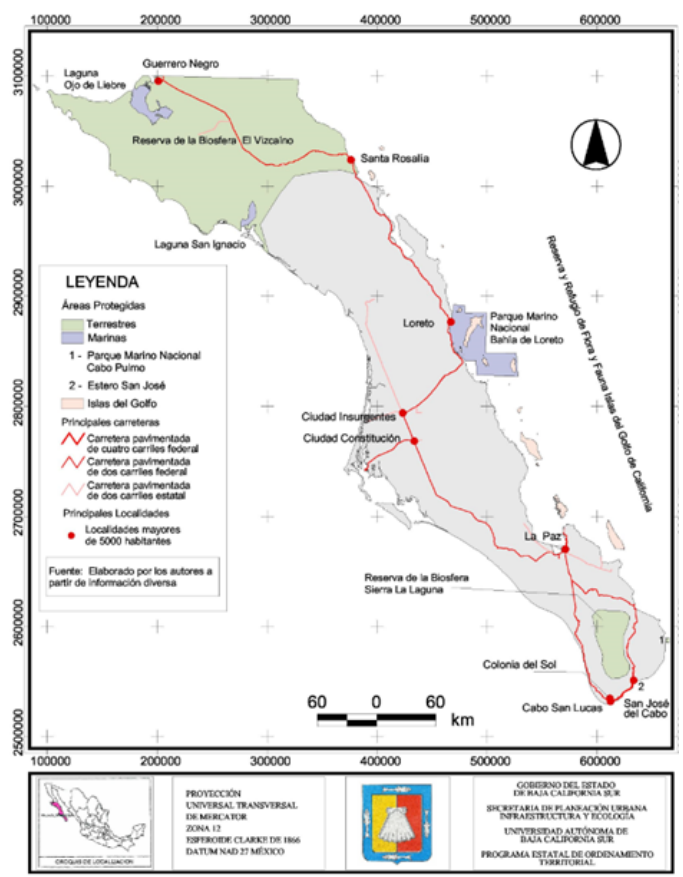

Figura 1: Localización de la Reserva de la Biosfera Sierra La Laguna, Baja California Sur, México.

Fuente: Tomado de Programa de Ordenamiento Ecológico Territorial, Baja California Sur. 
La REBIOSLA se puede considerar como una "isla" de vegetación en el entorno árido característico de la península de Baja California, resultado de un proceso geológico de separación del macizo continental, en el que la península y posteriormente la región de Los Cabos se vieron involucradas. Estos fueron factores que determinaron las características de aislamiento geográfico que presenta este territorio, y que establecieron las condiciones climáticas, orográficas y biológicas de los ecosistemas que prevalecen en la zona, y que favorecen la presencia de características importantes de endemismo en su flora y fauna. La historia geológica y ecológica de la Sierra La Laguna ha dado origen a ecosistemas únicos en el país (Padilla et al., 1988; citado en CONANP, 2003).

De norte a sur y a lo largo de aproximadamente 59 kilómetros, la Reserva es el parteaguas de dos cuencas hidrológicas, Arroyo Caracol-Arroyo Candelaria y La Paz-Cabo San Lucas, y constituye la división media entre los escurrimientos que drenan hacia el océano Pacífico y hacia el golfo de California o mar de Cortés. De acuerdo con la Comisión Nacional del Agua, de la Reserva se derivan seis cuencas hidrológicas que marchan en diversas direcciones, siendo la de mayor escurrimiento la cuenca San José (CONANP, 2003).

En la parte alta de la Reserva se presenta un clima templado subhúmedo con temperaturas promedio anuales de $14.7^{\circ} \mathrm{C}$ y un régimen de lluvias de verano, el porcentaje de lluvia invernal oscila entre 5 y $10.2 \mathrm{~mm}(8.3 \%)$, con verano fresco y largo y una oscilación anual de la temperatura extrema de $7.5^{\circ} \mathrm{C}$. En la parte baja de la Reserva se presenta un clima semiárido, cálido con una temperatura promedio anual de $22.7^{\circ} \mathrm{C}$, y un régimen de lluvias de verano, la lluvia invernal fluctúa entre 5 y $10.2 \mathrm{~mm}(9.1 \%)$ y una oscilación anual de la temperatura extrema de $9^{\circ} \mathrm{C}$. La Reserva presenta la mayor captación de agua producto de las lluvias en el Estado, el promedio anual en su parte alta oscila entre los $700 \mathrm{~mm}$ de promedio anual, a diferencia del resto del Estado que es de 100 a 150 mm (Coria, 1988; citado en CONANP, 2003).

La REBIOSLA es un área clave y representativa de la biodiversidad bajacaliforniana, ya que es el único bosque de coníferas, selva tropical, palmar, matorral y bosques de pino-encino de la península de Baja California y es una de las ANP mejor conservadas del Pacífico mexicano (CONANP, 2003). De la vegetación presente, 34 especies tienen uso maderable, siete industrial, 24 medicinales, 21 comestibles, ocho ornamentales, 157 de uso apícola y 136 forrajeras. Las prácticas de aprovechamiento de la vegetación en la zona se caracterizan por ser extractivas, con muy bajos niveles de manejo, que ocasionan una subutilización del recurso. Muchas de estas prácticas han provocado daños a los ecosistemas, e incluso algunas áreas dentro de la Reserva presentan daños por pérdida de suelo. A pesar de ello, este recurso sigue siendo la principal fuente de riqueza para los pobladores que ahí habitan.

Dadas sus características biogeográficas existe una amplia posibilidad de implementar, tanto proyectos de creación de infraestructura para la atención de los visitantes, como rutas, campamentos, actividades de turismo de aventura, senderos interpretativos o estancias en los ranchos de los habitantes de la reserva. La REBIOSLA no debe ser conceptuada como un esquema monofuncional o como zona cuya prioridad debe ser únicamente la conservación de la biodiversidad, pues ésta se distingue no sólo por su biodiversidad, sino también por su valor cultural, así como por ser refugio de flora y fauna, y fuente de sustento alimenticio y de recreación. Debe percibirse 
EL ECOTURISMO COMO BASE PARA EL DESARROLLO TERRITORIAL SOSTENIBLE EN LA RESERVA DE LA BIOSFERA SIERRA LA LAGUNA (REBIOSLA), BAJA CALIFORNIA SUR, MÉXICO
Ismael Rodríguez Villalobos Angélica Montaño Armendáriz Roberto González Sousa

como un espacio para la oportunidad de desarrollo rural, donde se puedan conciliar la conservación, el aprovechamiento de los recursos naturales y el mejoramiento de la calidad de vida humana.

\section{La ocupación del territorio de la Reserva de la Biosfera Sierra La Laguna}

Históricamente, la Sierra La Laguna fue asentamiento temporal de grupos nativos sedentarios. En el territorio de la Reserva se ubican diversas manifestaciones arqueológicas, que van desde simples entierros funerarios y pinturas rupestres, hasta algunas ruinas de antiguas moradas de los nativos que en ella habitaron. En la región de Santiago se pueden apreciar pinturas rupestres como dibujos de peces de diferentes tamaños, arcos y flechas y una serie de huellas de manos humanas en color rojo. Existen pinturas rupestres menos elaboradas en los siguientes lugares de la Reserva: La Cieneguita, El Álamo, La Burrera, Boca de la Sierra, El Cayuco y Ancón Largo, entre otros por ubicar. Otros entierros y restos óseos de importancia son los de Agua Amarga, Los Mártires, El Cerro, El Cantil, El Sauce, Los Sanjones y Sol de Mayo. Finalmente deben considerarse las "habitaciones" y los talleres, de los cuales hay buenos ejemplos en los siguientes lugares: La Pintada, La Tatema, Cerro de la Cruz, Mesa de Santiago, El Carrizalito, Sol de Mayo, Las Casitas, Palo Extraño y La Laguna (CONANP, 2003).

El origen del poblamiento de la Sierra La Laguna se ubica en las últimas décadas del régimen misional, iniciado en el siglo XVII y que marcó como una de sus principales consecuencias, la extinción de los habitantes originarios (cazadores-recolectores y pescadores). Los misioneros desarrollaron estrategias y técnicas para contrarrestar la aridez aprovechando los humedales. Los rancheros que habitan actualmente las serranías sudcalifornianas son los herederos directos de las estrategias de reapropiación socioterritorial de los misioneros. En esa medida, fundamentan aún su estructura económica y social en la ganadería de cambiadero (no estabulada) y en la horticultura (Castorena-Breceda, 2003, 2008).

A finales del siglo XVII el Real Consejo de Indias otorgó permiso real de colonización, y cristianización de los naturales a la Compañía de Jesús. La primera misión que se funda en la península fue Nuestra Señora de Loreto (1697), que luego sería la capital de todas las Californias; en 1720 se funda la misión de Nuestra Señora del Pilar de La Paz. Hacia fines del siglo XVIII, la decadencia de las poblaciones indígenas y el alto costo de mantenimiento de las misiones retrasaron el desarrollo de éstas bajo la administración dominica. La misión de Santiago que en 1779 había sido ubicada en San José Caduaño se abandonó definitivamente en 1795. Debido al movimiento de Independencia de México, de 1810 a 1821, el gobierno virreinal retiró el apoyo a las misiones.

La ocupación y asimilación económica del territorio de la Reserva por la actividad ganadera y el posible inicio del establecimiento de ranchos en la Sierra La Laguna se ubica a finales del siglo XVI, y se asocia este proceso al tipo de vegetación existente en el área y las condiciones ambientales que ahí se encuentran. Los primeros reales mineros de la zona y de la península se ubican en la segunda mitad del siglo XVIII en Cabezas de Arroyo Hondo (1751), que daría origen al poblado El Triunfo. Otras minas fueron San Pedro y San Pablo y hacia 1756 vecinos de Santa Ana iniciaron la 
explotación del mineral de plata en un lugar cercano, que luego llegó a convertirse en el actual pueblo de San Antonio. La falta de un desarrollo sostenido de las fuerzas productivas que solucionara los inconvenientes naturales de los yacimientos, evitó la explotación intensiva de la minería; algunos yacimientos tuvieron bonanzas efímeras, y otros sostuvieron niveles de producción por periodos mayores de diez años.

En cierta forma los reales mineros crecieron al amparo de la misiones de Santiago de los Coras y Santa Rosa de las Palmas, de donde los mineros se proveían de granos y bovinos. Esta relación favoreció el inicio de una creciente ganadería, estimándose que hacia 1775 los rebaños propiedad de algunos rancheros alcanzaban unos cinco mil animales. La ganadería criolla que hoy está presenta en la Sierra La Laguna, bien adaptada a las condiciones ambientales, es descendiente de razas celtíberas.

La localidad a la que se reconoce como cuna de la minería en la parte Sur del estado es El Triunfo, que tuvo su auge entre 1878 y 1879 al establecerse el Progreso Mininig Company para explotar las minas de oro y plata del lugar. La población aumentó hasta llegar casi a cinco 5 mil habitantes, los metales de circulación corriente fueron el oro y la plata que se producían en abundancia. El auge de la minería estimuló el comercio y la producción de hortalizas, la fruticultura y la producción de caña, fundamentalmente en las regiones de Todos Santos y Santiago.

A principios de 1883, aparece el primer conflicto social por la explotación minera, los vecinos de El Triunfo denunciaron claramente los efectos negativos sobre el medio ambiente asociado a la explotación minera. La sucesión de conflictos sociales, laborales y comerciales a causa de los propósitos de expansión de la compañía El Progreso precipitaron el cierre de la empresa en 1912, fecha que marca el declive de la localidad El Triunfo, ya que la región deja de ser económica y demográficamente importante.

Los aspectos históricos y culturales que más se destacan en la zona son la tradición heredada por los pobladores de la época colonial en sectores productivos como la minería, la ganadería, la talabartería, el fraguado y el forjado de hierro, el cultivo de hortalizas, el trapiche para la elaboración de piloncillo y la elaboración de conservas y queso. El poblamiento y la cultura de la región en que se enclava la Reserva, su patrimonio natural e histórico cultural, el cúmulo de valores creados en estos territorios, debe ser rescatado y protegido, para sustento del desarrollo cultural y material de la región y de México, y base de un importante desarrollo del turismo de naturaleza en sus diferentes modalidades (Fasio et al., 2012).

\section{La Reserva de la Biosfera Sierra La Laguna: principales características socioeconómicas}

Existen dos carreteras que dan acceso a la Reserva; la primera es la Federal No. 1 tramo San José La Paz, conocida como Carretera Transpeninsular (vía larga) y la segunda, la Estatal No. 17, tramo La Paz-Cabo San Lucas, conocida como Carretera Pacífico (vía corta); ambas comunican a los principales centros de población por el golfo de California: El Triunfo, San Antonio, San Bartolo, Santiago, Miraflores, San José del Cabo y Cabo San Lucas; y por el Pacífico, a las localidades de Todos Santos, Pescadero y Cabo San Lucas. Todas cuentan con servicio telefónico, correos y transporte todo el año. Existen además caminos de terracería que se derivan de las carreteras y que comunican a la mayoría de las comunidades y rancherías que se ubican dentro de la 
EL ECOTURISMO COMO BASE PARA EL DESARROLLO TERRITORIAL SOSTENIBLE EN LA RESERVA DE LA BIOSFERA SIERRA LA LAGUNA (REBIOSLA), BAJA CALIFORNIA SUR, MÉXICO
Ismael Rodríguez Villalobos Angélica Montaño Armendáriz Roberto González Sousa

Reserva. Su estado varía de bueno en la terracería y de regular a bueno en las brechas.

El territorio que abarca la Reserva está constituido por terrenos ejidales, de propiedad privada y nacionales; dentro de los primeros, ocho se ubican total o parcialmente dentro de la Reserva, de éstos, dos se localizan en las cercanías del poblado de Todos Santos, uno de ellos al noreste de éste y el otro al Oeste, los cuatro restantes, se encuentran en la vertiente del golfo de California entre los poblados de Miraflores y Santiago. Además, existen 35 terrenos de propiedad privada distribuidos dentro de la Reserva (CONANP, 2003). Respecto a los terrenos nacionales o de propiedad federal se tienen 10 zonas con estas características, en la parte central y media de la Sierra La Laguna. Sin embargo, la información capturada mediante el censo aplicado en el año 2003 por funcionarios de la Reserva revela la presencia de 6 ejidos, 13 condueñazgos, 80 particulares, 16 posesiones y 5 indefinidas. La situación de irregularidades en la tenencia de la tierra varían por su complejidad, destacando los predios que se encuentran en la categoría de "condueñazgo", que por incluir varios propietarios del mismo predio, todos aprovechan en forma desordenada los recursos naturales existentes.

Las principales actividades productivas se centran en las labores realizadas por jornaleros y la ganadería, ambas de hecho son complementarias entre sí, siendo la ganadería la actividad productiva dominante. Los jornaleros en número de 135, representaron más de la mitad de las 248 personas que realizan alguna actividad productiva en la Reserva según el censo realizado a principios de este siglo; le siguen los ocupados en la ganadería que suman 83 , nueve dedicados a la fruticultura y cinco a la talabartería, dos dedicados al comercio y el resto en las actividades del hogar (CONANP, 2003).

La agricultura en la Reserva se limita a la siembra de hortalizas (cebolla, tomate, chile, principalmente) básicamente para autoconsumo y sus excedentes se dan en trueque o bien se comercializan, porque los ingresos que se obtienen no repercuten en forma significativa en la economía familiar. La práctica de una ganadería extensiva en el área que comprende la zona de amortiguamiento de la Reserva es la actividad productiva predominante del sector primario. El ganado, adaptado a las condiciones ambientales de la región, pasta libremente durante la mayor parte del año en los agostaderos naturales, lo que ha propiciado un sobrepastoreo en más del $80 \%$ de la superficie apta para esta actividad. Además de ganado bovino, también se tienen hatos de ganado caprino sobre todo en rancherías cercanas a escurrimientos superficiales intermitentes, su número se ha incrementado en años recientes, derivado esto de programas implementados por la Secretaría de Agricultura, Ganadería y Desarrollo Rural.

En la Reserva es posible efectuar actividades de este tipo únicamente en la zona de amortiguamiento que comprende 79,917 hectáreas, a las que se les otorga un coeficiente de agostadero de 25 a 35 hectáreas por unidad animal. Es de resaltar que la cría de ganado bovino refleja más que una actividad altamente rentable, una situación de status y tradición. Según el censo de referencia, en el año 2000 la cabaña de ganado bovino ascendía a 7,498 cabezas y la de ganado caprino a 1,229. La cría de ganado porcino y ovino no supera las 600 cabezas (CONANP, 2003).

Otra de las actividades económicas de cierta importancia en la Reserva es el aprovechamiento forestal, maderable y no maderable, que constituye una actividad extractiva que se efectúa en forma legal e ilegal, pero que de alguna forma a quienes 
la realizan les reditúa ingresos extras que les permite sobrellevar épocas críticas. Los productos maderables son utilizados para la reparación y construcción de viviendas y palapas, instalación de cercas, reparación y construcción de corrales o bien como leña; los productos no maderables contribuyen igualmente a la obtención de ingresos económicos, sin embargo, a diferencia de los productos maderables, esta actividad se realiza, en la mayoría de los casos, mediante la colecta, cosecha o poda, dependiendo de la especie que se trate y su utilización va desde el techado de viviendas y construcción de palapas (colecta de hoja de palma); elaboración de condimentos, productos alimenticios y medicinales, bebidas, entre otros (CONANP, 2003).

La fruticultura es otra de las actividades que se practica en la Reserva. La misma se ha llevado a cabo desde los primeros asentamientos humanos que se establecieron en la región, de manera empírica y con fines de autoconsumo. La especie más común es el mango, de variedad criolla. Otras especies incluidas son: guayaba, papaya, aguacate, naranja y otros cítricos. Este tipo de fruticultura es de tipo marginal, con una gran proporción de árboles en edad avanzada. El producto obtenido se destina al mercado local y para la elaboración de conservas, como es el caso del mango, la guayaba y la papaya, en la región de San Dionisio y San Antonio de la Sierra.

Varios de los productos obtenidos de la flora existente en la Reserva son procesados por una industria artesanal para la producción de conservas y derivados lácteos. Estas actividades llevadas a cabo por las comunidades asentadas en la reserva, son derivadas de los excedentes de producción de huertos frutícolas familiares y de la producción de leche proveniente del ganado bovino y caprino, que les permite, eventualmente obtener ingresos adicionales para satisfacer sus necesidades básicas, así como enriquecer su dieta alimenticia. Esta producción tiene interés para quien la realiza de manera complementaria, bajo ciertas condiciones sociales y materiales muy particulares.

Si bien dentro de la Reserva no se realizan aprovechamientos mineros, sin embargo, sí se han efectuado exploraciones y denuncios mineros. De estos últimos, de acuerdo con la información obtenida a través de la Secretaría de Economía, se diferencian 21 denuncios mineros, 11 de ellos para exploración y 10 para explotación, con una superficie total de 15,596 hectáreas. Las superficies destinadas a explotación es aproximadamente de 2,247 ha. Respecto al potencial minero de la Reserva se tiene información sobre los yacimientos de mayor importancia que se encuentran localizados en la región noroeste de la Reserva en las comunidades La Junta, Las Paredecitas, El Saucito, El Veladero y Boca del Saucito, siendo vetas principalmente de oro y plata.

La práctica del turismo en el área de la Reserva no se ha desarrollado de una manera formal. Algunos de los rancheros que habitan la Reserva ofrecen sus servicios como guías y renta de bestias de carga, lo que les reditúa ingresos extras. Sin embargo se desenvuelven estos servicios turísticos en forma desorganizada y sin una preparación que les permita mayor profesionalismo, por lo que se requiere la organización de grupos y la creación de una mejor infraestructura básica. De consolidarse, pudiera representar una buena alternativa y tal vez una de las más viables, por representar ésta, una actividad de bajo impacto que no requiere de infraestructura y equipamientos sofisticados, así como por representar una fuente de ingresos importante que propiciaría la disminución del impacto causado por otras actividades productivas. La afluencia de visitantes estimada por temporada anual de octubre a abril es de cinco mil (Gutiérrez, 2011). 
EL ECOTURISMO COMO BASE PARA EL DESARROLLO TERRITORIAL SOSTENIBLE EN LA RESERVA DE LA BIOSFERA SIERRA LA LAGUNA (REBIOSLA), BAJA CALIFORNIA SUR, MÉXICO
Ismael Rodríguez Villalobos Angélica Montaño Armendáriz Roberto González Sousa

Otras actividades productivas presentes en el área de la Reserva son el comercio, el trabajo de jornaleros, así como la elaboración de artesanías que se basa fundamentalmente en el uso alternativo de los recursos naturales. El comercio que se da es un tanto informal por no ser una actividad preponderante entre los habitantes de la Reserva, inclusive aún se presenta "el trueque", que realizan intercambiando sus productos cosechados o elaborados. Entre los productos artesanales destacan talabartería, cerámica, tejido de palma y trabajos elaborados en madera, los que son comercializados en la mayoría de los casos bajo encargo o bien con los turistas que ocasionalmente transitan en la zona.

Se puede afirmar que el uso de los recursos naturales en la zona de amortiguamiento de la Reserva se ha centrado fundamentalmente en el aprovechamiento del agua, la flora y la fauna, la práctica del campismo y en menor proporción, el uso de los recursos minerales. De todos estos recursos, los que mayores beneficios aportan a las comunidades asentadas dentro de la Reserva lo constituyen el agua y la flora, pasando a segundo término la fauna, las actividades de campismo y los recursos minerales. La flora silvestre representa un recurso de subsistencia importante para el ranchero sudcaliforniano, debido a que de ella obtiene el forraje que da sustento a su actividad productiva fundamental, que es la ganadería extensiva. Asimismo, constituye la fuente de suministro de materias primas para la construcción y reparación de viviendas, instalación de cercos y corrales, obtención de plantas para aliviar o curar enfermedades, elaboración de implementos de trabajo, materia prima para el procesamiento de pieles y elaboración de artesanías, obtención de plantas alimenticias, entre otras.

La cacería de autoconsumo sobre especies de fauna silvestre constituye un complemento de proteínas importante en la dieta de los habitantes de la Reserva. Esta actividad se realiza durante los meses de marzo a agosto, coincidiendo con la época de estiaje en la región. Existen otros aprovechamientos que se realizan en forma aislada y que se basan fundamentalmente en aves canoras y de ornato. El uso de minerales (oro y plata) se da principalmente en las zonas de influencia de la Reserva (San Antonio y El Triunfo).

El campismo es una actividad que tradicionalmente se ha dado en la Reserva; se lleva a cabo en ciertas épocas del año (vacaciones de Semana Santa, octubre y noviembre) y se da en forma masiva, particularmente por grupos de jóvenes estudiantes de niveles medio, medio superior y superior, llegándose a registrar afluencias de hasta 1,700 visitantes en periodos cortos de cinco días. En general, es evidente que el uso que se les ha dado a los recursos naturales en esta zona ha sido de una manera tradicional, fundamentalmente debido a lo accidentado de la topografía y a la dificultad en la disponibilidad de agua suficiente para realizar sus actividades en forma intensiva, lo cual ha permitido que la Reserva se mantenga sin un deterioro significativo.

\section{La población, su distribución y tendencias observadas en su dinámica socioterritorial}

El territorio de la Reserva se encuentra compartido por dos municipios, al Norte La Paz y al Sur Los Cabos; por regiones se divide en Todos Santos, San Simón, San Antonio y Santiago. Una de las características demográficas de la reserva es la de contar con una gran cantidad de rancherías dispersas (106) y una pequeña comunidad de 100 habitantes (Ejido San Jorge). En censo realizado en el año 2000 en la Reserva reveló 
que en ella habitaban 175 familias con una población total de 738 habitantes, lo que da un promedio de 4,2 habitantes por familia. La estructura por sexo evidencia el predominio de la población masculina, 410 hombres y 328 mujeres. En los rangos de edades de 0 a 30 años se ubica casi $50 \%$ de la población (Tabla 1).

Tabla 1. Población por grandes grupos de edad y sexo de la Reserva de la Biosfera Sierra La Laguna.

\begin{tabular}{|c|c|c|c|}
\hline Rangos & Hombres & Mujeres & Total \\
\hline 0-15 & 102 & 108 & 210 \\
\hline 16 a 60 & 240 & 174 & 414 \\
\hline Más de 60 & 68 & 46 & 114 \\
\hline Total & 410 & 328 & 738 \\
\hline
\end{tabular}

Fuente: Censo de población de la Reserva de la Biosfera Sierra La Laguna, 2000

Sin embargo, en 2011 (ver tabla 2), en un total de 143 ranchos reportados, sólo se contabilizaron 545 habitantes; es decir, la población se redujo un 35\% en un período de 10 años. Un año después, un censo a 125 ranchos encontró que 90 son habitados permanentemente, 16 temporalmente, 8 no son habitados y 5 han sido abandonados (CONANP, 2011), lo que confirma el éxodo de pobladores en esas comunidades. De las cuatro regiones en que está dividida la Sierra La Laguna, la de Santiago es la que cuenta con la mayor cantidad de población.

Tabla 2. Resultados del censo sociodemográfico, 2011

\begin{tabular}{|l|c|c|c|c|c|c|c|c|}
\hline \multicolumn{1}{|c|}{ Región } & $\begin{array}{c}\text { No. de } \\
\text { ranchos }\end{array}$ & $\begin{array}{c}\text { Habitantes } \\
\text { por región }\end{array}$ & $\begin{array}{c}\text { Refrige- } \\
\text { rador } \\
\text { solar }\end{array}$ & $\begin{array}{c}\text { Iluminación } \\
\text { solar } \\
\text { fotovoltaica }\end{array}$ & Piso & $\begin{array}{c}\text { Estufa } \\
\text { ahorra- } \\
\text { dora de } \\
\text { leña }\end{array}$ & $\begin{array}{c}\text { Letrina } \\
\text { Eco- } \\
\text { lógica }\end{array}$ & $\begin{array}{c}\text { Huerto de } \\
\text { traspatio }\end{array}$ \\
\hline $\begin{array}{l}\text { Santiago } \\
\text { San } \\
\text { Dionisio })\end{array}$ & 26 & 205 & 7 & 11 & 5 & 17 & 7 & 7 \\
\hline $\begin{array}{l}\text { San } \\
\text { Antonio }\end{array}$ & 30 & 105 & 8 & 14 & 15 & 15 & 10 & 10 \\
\hline San Simón & 20 & 67 & 2 & 2 & 4 & 9 & 1 & 5 \\
\hline $\begin{array}{l}\text { Todos } \\
\text { Santos } \\
\begin{array}{l}\text { Santa } \\
\text { Gertrudis }\end{array}\end{array}$ & 67 & 168 & 5 & 7 & 4 & 35 & 5 & 5 \\
\hline Totales & 143 & 545 & 22 & 34 & 28 & 76 & 23 & 27 \\
\hline
\end{tabular}

Fuente: Censo de población de la Reserva de la Biosfera Sierra La Laguna, 2000

La población de las localidades de la Reserva presenta una tendencia decreciente en los últimos quince años, debido al constante flujo migratorio de jóvenes, tanto de hombres como de mujeres. La migración de la población se da en prácticamente todas las localidades de la Reserva, tanto de los que habitan en la vertiente del golfo, como en la del Pacifico. Los principales motivos son dos, uno de carácter laboral y el otro derivado por actividades de estudio. El constante movimiento migratorio laboral se da, por una parte, por la escasez de fuentes de empleo en sus lugares de origen, y por la otra, por una cada vez mayor oferta de empleo que se genera en el Corredor 
EL ECOTURISMO COMO BASE PARA EL DESARROLLO TERRITORIAL SOSTENIBLE EN LA RESERVA DE LA BIOSFERA SIERRA LA LAGUNA (REBIOSLA), BAJA CALIFORNIA SUR, MÉXICO
Ismael Rodríguez Villalobos Angélica Montaño Armendáriz Roberto González Sousa

Turístico Cabo San Lucas-San José del Cabo, donde la demanda de mano de obra no especializada es abundante con respecto al resto del estado, además de ser mejor remunerada. Los ingresos económicos de los habitantes de la reserva que reportan algún tipo de ocupación y que fueron declarados durante el censo aplicado en junio del 2000, son un tanto inciertos, debido a que no siguen un patrón salarial. Se observan ingresos promedio mensuales de $\$ 1,096.00$. Sin embargo, de acuerdo a las encuestas aplicadas a las comunidades que habitan dentro de la Reserva, se desprende que existe la posibilidad de que muchos de los habitantes que han tenido que emigrar, pudieran regresar a sus localidades si existiera la posibilidad de tener empleo o alguna fuente de ingresos derivada de actividades alternas que pudieran ofrecerse, vía programas institucionales de apoyo, entre otras.

El abastecimiento de agua en las comunidades de la Reserva se hace en su gran mayoría utilizando manantiales, arroyos, norias y pozos. Su conducción es por gravedad y a través de manguera hidráulica, son escasas las rancherías que cuentan con motobomba (CONANP, 2003). De las 175 familias que habitan dentro de la Reserva, $103(58.8 \%)$ se abastecen mediante plantas de energía solar, $18(10.3 \%)$ carecen de abastecimiento de energía eléctrica y $50(29 \%)$ lo hacen a través de la Comisión Federal de Electricidad, éstas últimas corresponden a la zona comprendida por el Ejido San Jorge y la comunidad El Chorro.

Los servicios médicos a los que acuden los habitantes de la Reserva son en su mayoría de carácter privado, o aquellos que el DIF les proporciona por medio de jornadas médicas. Solo dos casos (pensionados) reciben servicios médicos institucionales. El principal centro médico al que asisten los habitantes de esta zona es el Hospital General Juan María de Salvatierra, ubicado en la ciudad de La Paz, capital del estado. Los centros educativos se encuentran alejados de los asentamientos establecidos en el área de la Reserva, por lo que los niños y jóvenes reciben educación básica, a través de los centros educativos de preescolar, primarias, secundarias técnicas generales y tele-secundarias (albergues escolares), promovidos por la federación y el gobierno del estado, estos últimos ubicados en las comunidades de Santiago, Miraflores, Todos Santos, El Pescadero y Ejido Melitón Albañez. Para estar en posibilidades de continuar con estudios de nivel medio superior y superior, se deben trasladar a los centros educativos que se ubican en San José del Cabo, Todos Santos y La Paz (CONANP, 2003).

Algunas asociaciones de la sociedad civil han intervenido para mejorar la calidad de vida de los rancheros sudcalifornianos a partir de programas de acceso a agua limpia (49 ranchos de la Reserva), menor consumo de leña para cocinar y mejores condiciones sanitarias para las mujeres (76 ranchos), y programas de ordenamiento territorial, y organización comunitaria que ha incluido la prestación de servicios de turismo alternativo. Paralelamente, la Comisión Nacional de Áreas Naturales Protegidas (CONANP), órgano descentralizado de la SEMARNAT y encargado de conservar el patrimonio natural de la REBIOSLA, fomenta una cultura de la conservación y el desarrollo sustentable de las comunidades asentadas en su entorno. De esa forma, en la región se dispone de acceso a algunos recursos financieros y de apoyo legal que están orientados primordialmente a la conservación, y que inciden en las posibilidades de las comunidades para aprovechar esos recursos naturales de manera sustentable. 


\section{Los ranchos en el territorio de la REBIOSLA: caracterización y principales actividades que desarrollan}

En la REBIOSLA se reporta la existencia de 83 ranchos distribuidos 35 en la región Todos Santos, 25 en Santiago, 18 en San Antonio de la Sierra y cinco en San Simón. A estos ranchos están vinculados 431 personas. Como promedio para la reserva la cantidad de personas por rancho es de 5,19, con un mínimo en la región de San Antonio de la Sierra con 4,89 personas por rancho y un máximo en San Simón con 10,2 personas por rancho. Si se consideran los ranchos que no declaran número de personas o que el número de personas es igual a 0, esta cantidad de ranchos se incrementa a 128 y la cantidad de personas promedio por rancho es de 3,37 (Tabla 3).

Tabla 3. Total de ranchos y de personas declaradas en cada rancho en 2016

\begin{tabular}{|l|c|c|c|c|c|c|}
\hline \multirow{2}{*}{ Región } & \multicolumn{3}{|c|}{$\begin{array}{c}\text { Ranchos con personas } \\
\text { declaradas }\end{array}$} & \multicolumn{3}{c|}{$\begin{array}{c}\text { Ranchos que no declaran } \\
\text { personas en los mismos }\end{array}$} \\
\cline { 2 - 7 } & Ranchos & $\begin{array}{c}\text { Personas } \\
\text { declaradas en } \\
\text { los ranchos }\end{array}$ & $\begin{array}{c}\text { Personas } \\
\text { /rancho }\end{array}$ & Ranchos & $\begin{array}{c}\text { Personas } \\
\text { declaradas en } \\
\text { los ranchos }\end{array}$ & $\begin{array}{c}\text { Personas } \\
\text { /rancho }\end{array}$ \\
\hline $\begin{array}{l}\text { Todos } \\
\text { Santos }\end{array}$ & 35 & 137 & 3,91 & 62 & 137 & 2,21 \\
\hline San Simón & 5 & 51 & 10,20 & 14 & 51 & 3,64 \\
\hline $\begin{array}{l}\text { San Antonio } \\
\text { de la Sierra }\end{array}$ & 18 & 88 & 4,89 & 25 & 88 & 3,52 \\
\hline Santiago & 25 & 155 & 6,20 & 27 & 155 & 5,74 \\
\hline Totales & 83 & 431 & 5,19 & 128 & 431 & 3,37 \\
\hline
\end{tabular}

Fuente: Censo de población de la Reserva de la Biosfera Sierra La Laguna, 2000.

El análisis de las características de los ranchos que declaran personas en los mismos según la base de datos proporcionada por la dirección de la reserva se desglosa por regiones y revela la existencia de notables diferencias, a la vez que oportunidades para el desarrollo del turismo de naturaleza en sus distintas modalidades. En la región de Todos Santos se localizan 35 ranchos, que tienen como propietarios a 21 hombres, 12 mujeres y dos ranchos donde se mencionan propietarios de ambos sexos. Las actividades productivas para autoconsumo reportadas como principales son la ganadería en siete ranchos y la agricultura en la misma cantidad de ranchos; en dos ranchos ambas actividades se destacan como principales, siete tienen la producción de conservas y dulces regionales, cuatro la de lácteos, y dos sin producción declarada. Como actividades productivas para la venta a los visitantes se reporta en 18 ranchos la comercialización de productos lácteos y dulces, y los servicios turísticos en cinco ranchos. Los ranchos generalmente no cuentan con infraestructura productiva; de manera artesanal realizan la producción de lácteos; disponen de tres huertos, nueve corrales, dos ranchos poseen cabañas y alquiler de bestias en cuatro ranchos (LagunasVázques et al., 2013). 
EL ECOTURISMO COMO BASE PARA EL DESARROLLO TERRITORIAL SOSTENIBLE EN LA RESERVA DE LA BIOSFERA SIERRA LA LAGUNA (REBIOSLA), BAJA CALIFORNIA SUR, MÉXICO
Ismael Rodríguez Villalobos Angélica Montaño Armendáriz Roberto González Sousa

En la región de San Simón se reporta la existencia de cinco ranchos; de ellos cuatro tienen como propietarios a hombres y uno es propietaria una mujer. Las actividades principales de autoconsumo son agricultura, ganadería y elaboración de conservas y dulces regionales. Las actividades productivas para la venta son los productos lácteos, dulces regionales. Los ranchos no cuentan con infraestructura para la transformación de los recursos naturales, salvo queseras artesanales. Se dispone de tierras para siembra, corrales, cajones para apicultura y horno para pan.

En la región San Antonio se reportan 18 ranchos, 10 tienen como propietarios a hombres y los ocho restantes a mujeres. La agricultura y la ganadería se reportan como las actividades principales de autoconsumo, a lo cual se une la producción de lácteos y conservas y dulces regionales. Como actividades productivas para la venta se reportan la ganadería en cinco ranchos, la agricultura en uno, la elaboración de lácteos en cinco ranchos, de dulces y conservas en tres, la apicultura en uno. No se reporta la prestación de servicios turísticos en los ranchos de esta región. Se tiene la existencia de corrales en 16 ranchos, taller de costura en uno, huertos en cinco ranchos.

En la región Santiago existen 25 ranchos, 12 reportan como propietarios a hombres, igual número a mujeres; como actividades productivas para autoconsumo se destacan la ganadería y la agricultura; para la venta se declaran como actividades principales artesanía y talabartería en cuatro ranchos, servicios turísticos en cinco ranchos, la elaboración de dulces y lácteos en seis y productos cárnicos en dos. Los ranchos no disponen de infraestructura para la transformación de los recursos naturales, salvo medios artesanales para la producción de lácteos, conservas y dulces y machaca. Cinco ranchos disponen de corrales, se reporta la existencia de dos restaurantes, dos ranchos disponen de cabañas ecoturísticas (instalaciones rústicas para pernoctar los turistas separadas de la vivienda de los dueños del predio) y existen cuatro huertos de traspatio.

Una primera aproximación al estudio de los ranchos y habitantes existentes en la REBIOSLA destaca como hechos relevantes la presencia de la mujer como propietaria en 33 ranchos; de todos estos ranchos solo 10 tienen declaradas como una de sus actividades de comercialización a los visitantes la prestación de servicios turísticos (regiones Todos Santos y Santiago); las principales ofertas están asociadas a la comercialización de dulces, conservas y lácteos; en menor medida se reporta la comercialización de machaca y otros derivados cárnicos. Del total de ranchos existentes en la reserva aproximadamente 11 cuentan con huertos con distinto grado de tecnificación; 33 de los ranchos disponen de corrales para la ganadería y las dos actividades principales en la región son la agricultura y la ganadería; la infraestructura productiva existente en la mayoría de los ranchos es de carácter artesanal, lo que limita sus volúmenes de producción y prestación de servicios (alojamiento, restaurantes, guías, etc.) al turista. En la investigación no se detecta la formación de un sistema integrado de producción y prestación de servicios turísticos más allá de los límites territoriales de cada rancho, aunque la presencia en la región Santiago de ranchos con una modalidad de servicio que considera brazalete y alimentación incluida, puede valorarse como un incipiente sistema relativamente simple en formación de prestación de servicios turísticos que debe ser potenciado en el desarrollo de sus relaciones socio y económicoterritoriales. 
Según la base de datos proporcionada por la Dirección de la Reserva se declara la prestación de servicios turísticos en 10 ranchos, cinco de ellos localizados en la región de Todos Santos y otros cinco en la región Santiago. En la región Todos Santos cinco ranchos declaran en el conjunto de sus actividades productivas para la comercialización, la prestación de servicios turísticos, sólo dos de ellos como parte de su infraestructura poseen cabañas y palapas, el resto disponen de bestias mulares para el movimiento de los visitantes. En cuanto a las actividades que realizan para su autoconsumo se señalan la ganadería y la elaboración de productos y solo en uno de ellos la ganadería se desarrolla de conjunto con la agricultura. Como actividades complementarias para la venta se declara la elaboración de productos lácteos, y en uno de sus ranchos, la artesanía. La infraestructura que poseen, además de las cabañas antes mencionadas, la integran corrales para las mulas. Otras producciones que se unen al alquiler de cabañas y mulas, y que contribuyen al ingreso de los ranchos son la comercialización de quesos y la venta de artesanía.

En la región Santiago cinco ranchos declaran en el conjunto de sus actividades para la comercialización la prestación de servicios turísticos, con la presencia de tres restaurantes, y en dos de ellos, cabañas para su alquiler a los visitantes donde se incluye brazalete y alimentación, lo que revela la presencia de un mayor nivel de desarrollo de la cultura turística en sus propietarios. En cuanto a las actividades que realizan para su autoconsumo se señalan agricultura, elaboración de productos lácteos, elaboración de conservas (dulces regionales) y la ganadería. Como actividades complementarias para la venta se declaran la ganadería y la talabartería. La infraestructura que poseen, además de las cabañas y restaurantes antes mencionadas, la integran corrales y huertos. Otras producciones que se unen al alquiler de cabañas y la venta en restaurantes, está relacionada con el servicio de brazalete y alimentación incluida, lo que favorece los vínculos de estos ranchos con otros productores localizados en el área de la reserva y fuera de ella, y que contribuyen al ingreso monetario en los ranchos.

\section{Objetivos de los proyectos PRODERS, PROCODES y CONAFOR ejecutados en el territorio de la REBIOSLA entre los años 2003 y 2016.}

El Programa de conservación para el desarrollo sostenible (Procodes) es un subsidio que beneficia a las comunidades residentes en áreas naturales, creado como un instrumento de política pública para el impulso al desarrollo sustentable. Se adquiere a través de la Comisión Nacional de Áreas Naturales Protegidas (CONANP). Su propósito es promover la conservación de los ecosistemas y su biodiversidad en ANP. Los Proders (Proyectos para el desarrollo sostenible), ahora Procodes, dieron inicio en 2001. Su objetivo fue fomentar el aprovechamiento sostenible en lo ambiental, económico y social de las comunidades de las ANP, generando oportunidades productivas alternativas que contribuyen a mejorar la calidad de vida de los habitantes ((Meza, M. (s/f).

En líneas generales, la orientación que mantuvieron los proyectos Proders se estructuró en tres direcciones principales: fomentar la participación de las comunidades, promover proyectos ecoproductivos y actividades productivas alternativas y coordinar la participación gubernamental e institucional en las ANP. Los proyectos Procodes en la REBIOSLA tienen en la actualidad tres direcciones principales de trabajo: 
EL ECOTURISMO COMO BASE PARA EL DESARROLLO TERRITORIAL SOSTENIBLE EN LA RESERVA DE LA BIOSFERA SIERRA LA LAGUNA (REBIOSLA), BAJA CALIFORNIA SUR, MÉXICO
Ismael Rodríguez Villalobos Angélica Montaño Armendáriz Roberto González Sousa

producciones artesanales a partir recursos locales, infraestructura de servicios para la práctica del ecoturismo (servicio de guía y renta de bestias, renta de tiendas de campañas, etc.) y producciones de autoconsumo y para restaurantes rústicos. La orientación de los proyectos financiados por Conafor (Comisión Nacional Forestal) tiene como destino la protección y conservación del patrimonio natural.

La orientación de los proyectos Proders, Procodes y de Conafor solicitados y ejecutados en la región Todos Santos durante más de una década y según el monto de inversiones ejecutadas, como se verá en párrafos siguientes, revela su orientación a la protección y conservación del patrimonio natural y, son escasos los proyectos orientados al ecoturismo, lo que puede verse como una limitante para el desarrollo en la región.

De estos proyectos se declararon como proyectos ecoturísticos 24 , cuya orientación transita desde la construcción de cabañas, restaurantes hasta infraestructura ecoturística como senderos, compra de bestias y equipos para el servicio de guías a los visitantes y alcanzaron un monto de 2,198 miles de pesos, el 17,1\% de la inversión total realizada en los ranchos de la región. A diferencia de las regiones Todos Santos, San Simón y San Antonio, existe un número importante de proyectos orientados al ecoturismo, lo que podría sustentar la formación de una estructura productiva que orientada en su integralidad a la cooperación entre los productores y ranchos, dinamizaría la economía en la región Santiago, y crearía mayores y mejores oportunidades para su desarrollo como destino del turismo de naturaleza.

En la región se realizaron 60 proyectos entre los años 2004 y 2016, con el mayor número de proyectos en los años 2010 con 12 y en 2013 con 11 proyectos. A partir del año 2010 se nota un auge en la cantidad de proyectos que se ejecutan y que representan más del 80\% del total ejecutado en la región. La distribución de los proyectos por ranchos no muestra fuertes contrastes. Se destaca el rancho Sta. Gertrudis con seis proyectos, los ranchos La Rueda, Los Taraices y Sto. Domingo con cuatro proyectos en cada uno de ellos. Con tres proyectos se pueden mencionar los ranchos Boca del Saucito, El Ademado, El Mezcalito 2, La Esperanza, Texcalama 1 y Teresa. Los restantes ranchos muestran dos o menos proyectos, lo que significa que 36 de los proyectos ejecutados en la etapa analizada se concentraron en 9 ranchos. El monto total de los recursos dedicados a todos los proyectos ejecutados en la región ascendió aproximadamente 6,769 miles de pesos, para una media por proyecto de 113 miles de pesos (Tabla 4). 
Tabla 4. Distribución de los proyectos ejecutados por ranchos en la región Todos Santos entre 2004 y 2016.

\begin{tabular}{|l|c|c|}
\hline \multicolumn{1}{|c|}{ Ranchos } & Proyectos ejecutados & Inversión total (pesos) \\
\hline Sta. Gertrudis & 6 & 966260 \\
\hline La Rueda & 4 & 905000 \\
\hline Los Taraices & 4 & 246700 \\
\hline Sto. Domingo 1 & 4 & 324600 \\
\hline Boca del Saucito & 3 & 332080 \\
\hline El Ademado & 3 & 400000 \\
\hline El Mezcalito 2 & 3 & 280000 \\
\hline La Esperanza & 3 & 73000 \\
\hline Texcalama 1 & 3 & 255200 \\
\hline Teresa & 3 & 120570 \\
\hline Texcalama 2 & 2 & 360000 \\
\hline La Cieneguita de Todos Santos & 2 & 158000 \\
\hline El Saucito & 2 & 308000 \\
\hline Sto. Domingo 4 & 2 & 120000 \\
\hline $\begin{array}{l}\text { Sub total en ranchos } \\
\text { con dos o más proyectos }\end{array}$ & 14 & 4849410 \\
\hline Total en la región Todos Santos & 60 & 6769308 \\
\hline
\end{tabular}

Fuente: Base de datos de proyectos de inversión de la Reserva de la Biosfera Sierra La Laguna, 2016.

En el rancho Sta. Gertrudis, mayor receptor de proyectos e inversión en esta región, estos se orientaron principalmente a medidas de protección de los suelos y captura del recurso hídrico (construcción de presas de piedra acomodada), incorporación de estufas ahorradoras de leña, recolección de desechos sólidos, establecimiento de huertos de traspatio y talleres para la transformación de los recursos naturales (producción de machaca). En una segunda posición por el monto de la inversión recibida en la ejecución de cuatro proyectos se destaca el rancho La Rueda, donde se combinan proyectos orientados a conservación de los recursos forestales (Programa PROARBOL), huertos de traspatio y proyectos ecoturísticos (construcción de cabañas, restaurante).

Los ranchos que ejecutaron tres proyectos en el período analizado enfocaron su actuación principalmente a proyectos de protección de la naturaleza (construcción de presas de piedra acomodada y de estufas ahorradoras de leña, vivero de palo de arcos); utilización de los recursos del territorio (instalación de apiarios, elaboración de dulces, quesos, machaca, talabartería, huertos comunitarios, etc.) y, en mucha menor medida, a proyectos dirigidos al ecoturismo (construcción de cabañas ecoturísticas), lo que evidencia la escasa motivación de los solicitantes de proyectos hacia el desarrollo de esta actividad. Se declararon como proyectos ecoturísticos en esta región solo ocho, enfocados a la construcción de cabañas, restaurante, compra de bestias y construcción 
EL ECOTURISMO COMO BASE PARA EL DESARROLLO TERRITORIAL SOSTENIBLE EN LA RESERVA DE LA BIOSFERA SIERRA LA LAGUNA (REBIOSLA), BAJA CALIFORNIA SUR, MÉXICO
Ismael Rodríguez Villalobos Angélica Montaño Armendáriz Roberto González Sousa

de infraestructura de campamento, concentrados en los ranchos El Ademado, La Rueda. La Cienaguita de Todos Santos, El Guamuchilito, Sto. Domingo y Texcalama 1.

La orientación de estos proyectos ejecutados en la región Todos Santos según el monto de inversiones ejecutadas, revela la búsqueda de una mayor protección de los suelos con la aplicación de medidas para la protección de las áreas forestales, medidas anti erosivas y para la captura del recurso hídrico y un mayor aprovechamiento de los recursos naturales existentes en este territorio. Esta región se aproxima a las regiones San Simón y San Antonio, donde existe un número importante de los proyectos ejecutados orientados a la protección y conservación del patrimonio natural. Si bien se han ejecutado una menor cantidad de proyectos orientados al ecoturismo, lo que podría verse como una limitante para el desarrollo de esta actividad en la región, el hecho de que la mayoría de los proyectos se enfocan a conservar y valorizar el patrimonio natural, y al desarrollo de producciones locales a partir de recursos explotados en los ranchos, puede sustentar la formación de una estructura productiva que orientada en su integralidad a la cooperación entre los productores y ranchos dinamizaría la economía en la región Todos Santos, y crearía mayores y mejores oportunidades para su desarrollo como destino del turismo de naturaleza.

En el período 2004-2016 se realizaron 23 proyectos Proders, Procodes y de Conafor en la región de San Simón por un monto total de 3,311 miles de pesos, para una media de 144 miles de pesos. Distribuidos por años se tiene que entre el 2009 y el 2012 se ejecutaron 16 proyectos para un 70\% del total realizado en esta región. Se destaca que ocho de esos proyectos en diferentes años se ejecutaron en el rancho Las Flores por un monto de 2,653 millones de pesos orientados a acciones de conservación y restauración de suelos, represas y cursos de capacitación para el manejo de UMA en el ejido San Simón dedicado a la cría de venado, manejo de huertos de traspatio, entre otros (2004, 2007, 2009, 2010, 2011, 2012 y Conafor). Le sigue por el monto de la inversión el rancho San Fernando que realizó dos proyectos, el primero en el 2005 dirigido a la construcción de presas de piedra y el segundo en 2016 para el desarrollo de un huerto comunitario para una inversión total en el rancho de 239,512 pesos.

El rancho Jesús María obtuvo tres proyectos dirigidos al desarrollo de apiarios y la compra de núcleos de abejas $(2009,2010,2012)$ por un monto de 90 mil pesos. El rancho Bella Vista obtuvo tres proyectos en esos mismos años, dirigidos a la creación de huertos de traspatio y la adquisición de su tecnología por un monto de 117,540 pesos. Igualmente el rancho La Palmilla 1 con tres proyectos dedicados mayormente al desarrollo de huertos y la capacitación técnica para ello (2007, 2009 y 2012), con una inversión de 102,540 pesos. El rancho Casa Verde realizó dos proyectos (2009 y 2010) dirigidos al establecimiento de huertos de traspatio y una inversión de 40 mil pesos; el rancho Palmilla 2 desarrolló dos proyectos por un monto de 53,360 pesos, dirigidos al establecimiento de apiarios (2009 y 2011). La orientación de estos proyectos ejecutados revela la búsqueda de un mayor aprovechamiento de los recursos naturales existentes en este territorio, lo que podría sustentar la formación de una estructura productiva que orientada en su integralidad a la cooperación entre los productores y ranchos dinamizaría la economía en la región de San Simón, y crearía mayores y mejores oportunidades para su desarrollo como destino del turismo de naturaleza. 
En la región se realizaron 52 proyectos, el 70\% se concentró en los años 2010 a 2016 (70\%), con un máximo de 8 proyectos en el 2014. El monto total de los recursos dedicados a estos proyectos ascendió aproximadamente 4,819 miles de pesos, para una media de 93 miles de pesos, con los mayores valores a partir del 2014. La distribución de los proyectos por rancho tiene entre sus principales receptores a los ranchos San José del Rancho con 6 proyectos y un monto de inversión por proyectos ascendente a 814 miles de pesos; rancho Casas Viejas con 5 proyectos para una inversión de 215 miles de pesos y rancho Los Correderos con 4 proyectos y una inversión de 376 miles de pesos. Los restantes ranchos han ejecutados 3 proyectos (4 ranchos), dos proyectos (9 ranchos) y un proyecto ( 7 ranchos). El monto de inversión mayor para proyectos le correspondió en el período analizado al rancho San José del Rancho ascendente a 893 miles de pesos, seguido del rancho las Matancitas con 380 miles de pesos y el rancho Casa Viejas con 325 miles de pesos.

Los proyectos en el rancho San José del Rancho se enfocaron a la capacitación para la transformación de los recursos naturales, monitoreo y conservación de especies, establecimiento de Huertos Comunitarios, medidas anti erosivas y para la captación de agua, entre otros. En el rancho Las Matancitas se orientaron a la construcción de huertos de traspatio y medidas anti erosivas y para la captación de agua. En el rancho Casas Viejas los proyectos se dirigieron a la transformación de los recursos de la naturaleza, la actividad apícola, la elaboración de productos lácteos y a la capacitación de Operación de Empresas Ecoturísticas.

Las mayores inversiones por proyecto se realizaron en el rancho San José del Rancho por un monto de 330 miles de pesos dedicados a la construcción de represas de piedra acomodada y al monitoreo de especies (murciélagos); también inversiones de mayor peso en este territorio se realizaron en los ranchos Matancitas, Los Corredores, San Venancio y La Esperanza dedicadas a la construcción de Represas de Piedra Acomodada; en los ranchos Casas viejas, Los Nogales, Los Correderos 2 y Agua de San Antonio a talleres para la transformación de recursos naturales (machaquera, quesera, elaboración de dulces regionales establecimiento de apiarios, entre otras). Las inversiones en estos ranchos representaron el 47\% del total realizado en la región de San Antonio entre los años 2003 y 2016, con el predominio de aquellas realizadas a partir del año 2010 .

Según el objetivo para el cual fueron solicitados estos proyectos en la región de San Antonio, se destaca que 17 de ellos se dedicaron a la construcción (incluye capacitación) de huertos de traspatio; ocho de ellos se orientan a la construcción de represas con piedras acomodadas, igual número a machaqueras y la elaboración de cárnicos y cinco a proyectos de equipamiento para la fabricación de quesos. Los restantes proyectos se orientan a la producción de dulces, construcción de apiarios, entre otros. Dada la orientación de esta investigación se destaca en el rancho Casas Viejas la realización de un proyecto para la capacitación de operación de empresas ecoturísticas.

La orientación de estos proyectos ejecutados en la región de San Antonio revela la búsqueda de una mayor protección de los suelos con la aplicación de medidas anti erosivas y de captación de agua; un mayor aprovechamiento de los recursos naturales existentes en este territorio, lo que podría sustentar la formación de una estructura 
EL ECOTURISMO COMO BASE PARA EL DESARROLLO TERRITORIAL SOSTENIBLE EN LA RESERVA DE LA BIOSFERA SIERRA LA LAGUNA (REBIOSLA), BAJA CALIFORNIA SUR, MÉXICO
Ismael Rodríguez Villalobos Angélica Montaño Armendáriz Roberto González Sousa

productiva que orientada en su integralidad a la cooperación entre los productores y ranchos dinamizaría la economía en la región de San Antonio, y crearía mayores y mejores oportunidades para su desarrollo como destino del turismo de naturaleza

En la región Santiago se realizaron 79 proyectos en el marco de los programas Procedes, Procodes, Conafor y Conanza entre 2004 y 2016, concentrados más del 60\% de ellos entre los años 2007 y 2013, con un máximo de nueve proyectos en el año 2011. El monto total de los recursos dedicados a estos proyectos ascendió aproximadamente 12,856 miles de pesos, para una media por proyecto de 163 miles de pesos. Los años con ocho o más proyectos ejecutados corresponden a 2008, 2011 y 2012, lo que podría revelar una tendencia decreciente en las inversiones por proyectos de estas fuentes en la región y puede afectar su desarrollo. Del total de proyectos ejecutados, 41 proyectos se desarrollaron en seis de los ranchos de la región, 12 de ellos en el rancho San Jorge y ocho en el rancho El Chorro (Aguacaliente), lo que evidencia una marcada concentración territorial de los proyectos ejecutados en determinados ranchos de la región y la falta de incorporación de los restantes ranchos a estos programas para el desarrollo en la REBIOSLA (Tabla 5).

Tabla 5. Distribución de los proyectos ejecutados por ranchos en la región Santiago

\begin{tabular}{|l|c|c|}
\hline \multicolumn{1}{|c|}{ Rancho } & $\begin{array}{c}\text { Proyectos } \\
\text { ejecutados }\end{array}$ & Inversión total (pesos) \\
\hline El Chorro (Aguacaliente) & 8 & 712975 \\
\hline Las Vinoramas (Aguacaliente) & 4 & 502000 \\
\hline Mata Gorda & 3 & 2802810 \\
\hline El Aserradero & 6 & 178500 \\
\hline El Chinal & 5 & 396400 \\
\hline El Chinal Viejo & 4 & 641000 \\
\hline El Paso & 4 & 310080 \\
\hline El Refugio & 3 & 383400 \\
\hline Encino Gordo & 5 & 294000 \\
\hline La Acacia & 4 & 698258 \\
\hline Sol de Mayo & 4 & 11838256 \\
\hline San Jorge & 12 & 12856466 \\
\hline $\begin{array}{l}\text { Sub total en ranchos } \\
\text { con tres o más proyectos }\end{array}$ & 62 & \\
\hline Total en la región Santiago & 79 & \\
\hline
\end{tabular}

Fuente: Base de datos de proyectos de inversión de la Reserva de la Biosfera Sierra La Laguna, 2016. 
Los proyectos en el rancho San Jorge se enfocaron mayormente a la instalación de apiarios (6), producción de dulces, huertos comunitarios e instalación de estufas ahorradoras de leña; en el rancho El Chorro (Aguacaliente) cinco proyecto se orientaron al ecoturismo (cabañas y restaurante), dos para la transformación de recursos naturales (dulces, artesanías, carpintería) y uno para la construcción de un Apiario; en el rancho El Aserradero, tres proyectos para el desarrollo de infraestructura ecoturística y dos huertos comunitarios; en el rancho El Chinal, tres para producción de dulces, uno para huerto de traspatio y otro para plantación de palo de arco; en el rancho El Chinal Viejo, un proyecto dirigido al ecoturismo (restaurante), un apiario y otros a la construcción huerto de traspatio, carpintería e instalación de estufas ahorradoras de leña; en el rancho El Paso, un proyecto dirigido al ecoturismo (equipamiento y compra de bestias para guía), uno a la producción de dulces regionales y otro al desarrollo de medidas contra incendios; en el rancho El Refugio, dos proyectos ecoturísticos (restaurante y sendero); en el rancho El Encino Gordo, un proyecto dirigido al ecoturismo, dos a la instalación de apiarios y otro para el desarrollo de la artesanía. La orientación de los proyectos en los restantes ranchos de la región se enfoca en las direcciones antes mencionadas principalmente.

Se declararon como proyectos ecoturísticos 24 proyectos, cuya orientación transita desde la construcción de cabañas, restaurantes hasta infraestructura ecoturística como senderos, compra de bestias y equipos para el servicio de guías a los visitantes y alcanzaron un monto de 2,198 miles de pesos, el 17,1\% de la inversión total realizada en los ranchos. Estos proyectos ecoturísticos se iniciaron en el año 2003 y es de destacar que solo 11 de ellos se promovieron a partir del año 2010, lo que evidencia una lenta dinámica en esta actividad para el desarrollo de la región. Territorialmente se concentran en cinco ranchos que ejecutaron dos o más proyectos (El Chorro-Aguacaliente, El Aserradero, La Acacia, Sol de Mayo y El Refugio).

Las mayores inversiones por rancho se realizaron en el rancho San Jorge con cerca de 4,3 millones de pesos, lo que representa el 34\% de la inversión total en la región. Es de destacar que estas inversiones estuvieron relacionadas con la utilización de los recursos de la naturaleza, su protección y conservación y no directamente enfocadas hacia el ecoturismo. El segundo rancho según el monto de las inversiones por proyecto en esta región es el rancho Mata Gorda con el 22\% del total, y se relacionan estas inversiones con el Programa PROARBOL (1,746 miles de pesos), curso de capacitación para el desarrollo forestal (70 miles de pesos) y compensación por cambio de uso de suelo forestal (879 miles de pesos).

La orientación de estos proyectos ejecutados en la región de Santiago según el monto de inversiones ejecutadas, revela la búsqueda de una mayor protección de los suelos con la aplicación de medidas para la protección de las áreas forestales y un mayor aprovechamiento de los recursos naturales existentes en este territorio. No obstante y a diferencia de las regiones Todos Santos, San Simón y San Antonio, existe un número importante de proyectos orientados al ecoturismo, lo que podría sustentar la formación de una estructura productiva que orientada en su integralidad a la cooperación entre los productores y ranchos dinamizaría la economía en la región Santiago, y crearía mayores y mejores oportunidades para su desarrollo como destino del turismo de naturaleza.

Según informe elaborado por la dirección de la reserva referido al mejoramiento de 
EL ECOTURISMO COMO BASE PARA EL DESARROLLO TERRITORIAL SOSTENIBLE EN LA RESERVA DE LA BIOSFERA SIERRA LA LAGUNA (REBIOSLA), BAJA CALIFORNIA SUR, MÉXICO
Ismael Rodríguez Villalobos Angélica Montaño Armendáriz Roberto González Sousa

la calidad de vida del ranchero sudcaliforniano, se han realizado una gran diversidad de proyectos con financiamiento proveniente de fuentes externas a la reserva, que sin lugar a dudas pueden incidir favorablemente en el desarrollo del turismo de naturaleza en las regiones que forman parte de la reserva, donde se destacan los ranchos de la región Santiago por la participación proporcionalmente relevante entre los ranchos beneficiados (Tabla 6). Estos proyectos se complementan con proyectos Proders, Procodes y de Conafor ejecutados entre los años 2003 y 2016, fuertemente vinculados al patrimonio natural, su conservación, utilización racional y sostenible, un número importante de ellos directamente relacionados a la actividad del ecoturismo.

Tabla 6. Ranchos beneficiados con el programa de mejoramiento de la calidad de vida del ranchero sudcaliforniano. Año 2016

\begin{tabular}{|l|c|c|c|c|c|c|c|}
\hline Región & \multirow{2}{*}{$\begin{array}{c}\text { Número } \\
\text { de } \\
\text { ranchos }\end{array}$} & \multicolumn{6}{|c|}{ Ranchos beneficiados } \\
\cline { 3 - 8 } & & $\begin{array}{c}\text { Refrigerador } \\
\text { solar }\end{array}$ & $\begin{array}{c}\text { Iluminación } \\
\text { fotovoltaica }\end{array}$ & Piso & $\begin{array}{c}\text { Estufa } \\
\text { ahorradora }\end{array}$ & $\begin{array}{c}\text { Letrina } \\
\text { ecológica }\end{array}$ & $\begin{array}{c}\text { Huerto de } \\
\text { traspatio }\end{array}$ \\
\hline $\begin{array}{l}\text { Todos } \\
\text { Santos }\end{array}$ & 62 & 4 & 6 & 2 & 38 & 4 & 8 \\
\hline $\begin{array}{l}\text { San } \\
\text { Simón }\end{array}$ & 25 & 5 & 9 & 10 & 14 & 7 & 9 \\
\hline $\begin{array}{l}\text { San } \\
\text { Antonio }\end{array}$ & 14 & 1 & 1 & 3 & 9 & 2 & 4 \\
\hline Santiago & 27 & 5 & 7 & 6 & 70 & 6 & 5 \\
\hline Totales & 128 & 15 & 23 & 21 & 131 & 19 & 26 \\
\hline
\end{tabular}

Fuente: Base de datos de proyectos de inversión de la Reserva de la Biosfera Sierra La Laguna, 2016.

\section{La comercialización del ecoturismo en la Reserva de la Biosfera La Laguna}

La comercialización del destino, los servicios y productos que se ofrecen en la Reserva se realiza por operadores-agentes turísticos externos que promueven la zona y ofrecen en ella sus servicios a través de internet, mediante medios impresos como revistas y a través de los operadores locales. El medio más utilizado para brindar información sobre la Sierra La Laguna es internet, a la cual se acude desde diferentes regiones del planeta para buscar información sobre el lugar, las características del destino y del producto turístico que se oferta.

Las agencias - operadores externos que ofrecen actividades y servicios dentro de la Sierra La Laguna, que disponen de permiso por la CONANP para ofertar este destino y realizan un pago para operar dentro del área son: Mexcapade S de RL de CV, Eco Adventures, Terramar, Baja Sierra Adventure y Baja Wild. (Ledesma, M., 2014).

Para el desarrollo de su actividad cuentan con página de internet que contiene información relativa al servicio que ofrecen (Tabla 7). Los operadores locales pueden mantener vínculos comerciales con una cantidad variable de operadores externos (intermediarios). Se destaca el caso del operador local del Rancho Sol de Mayo, una 
de las empresas más grandes de ecoturismo dentro de la Sierra La Laguna, que trabaja con 18 operadores externos, y con todos ellos tiene un convenio escrito. Por esta intermediación recibe el $90 \%$ de sus clientes.

En las conclusiones de su investigación Ledesma (2014) destaca que la Sierra La Laguna cuenta ya con diversos productos y servicios y una comunidad de rancheros que cada vez más apuestan su economía al turismo. Sin embargo, pese al apoyo de las instituciones gubernamentales como la CONANP y el gobierno del estado de Baja California Sur y de otros actores de la sociedad civil y privada para incentivar la autogestión y emprendimiento en los estos rancheros, encontramos que algunos de estos proyectos han fracasado. Los casos de las cabañas de Agua Caliente, Melitón Albáñez y San Antonio de la Sierra muestran este fracaso, ya que existen las instalaciones pero no la demanda, y han debido cerrarlas temporalmente o permanentemente.

Por otro lado, se revelan experiencias positivas como en los casos Rancho Sol de Mayo, Rancho El Refugio, donde sus propietarios tienen grados universitarios y han puesto empeño en la promoción y comercialización de sus servicios teniendo como resultado mayor demanda y éxito en sus empresas. En el 2011 algunos prestadores de servicios, con los dueños de estos dos últimos ranchos a la cabeza, crearon una Cadena de Ecoturismo con 9 prestadores involucrados, de los cuales sólo uno no se localiza en la Sierra La Laguna ni en sus alrededores.

La adecuada comercialización de los servicios es un aspecto crucial para la sustentabilidad económica de los proyectos. Se destaca un común denominador con los servicios de turismo más exitosos dentro de la Sierra La Laguna: el uso de internet y teléfono como herramientas indispensables de la comercialización de sus productos. No obstante lo anterior, todos coincidieron en que la herramienta más poderosa de la promoción ha sido la de boca a oído de los mismos clientes.

Otro aspecto importante a remarcar es el idioma como barrera entre los servicios y el mercado internacional. Los prestadores que ofrecen la información en dos idiomas, logran una ventaja competitiva. Esto revela la importancia de la capacitación como parte fundamental de la oferta de servicios. La capacitación constante y específica sobre las necesidades y especialidad del servicio son importantes para ofrecer una calidad de servicio que asegure la satisfacción del cliente y con esto promueva la promoción de boca a oído.

Si retomamos el concepto de ecoturismo podemos encontrar que el ecoturismo debe ser ambientalmente y socialmente responsable. Como una nueva fuente de empleo, es importante asegurar que esta práctica sea viable a largo plazo y brinde beneficios socioeconómicos bien distribuidos con oportunidades de empleo estables y obtención de ingresos y servicios sociales para toda la comunidad. Una de las alternativas dirigida al logro de la sostenibilidad de estos emprendimientos locales se tiene en la creación de un sistema territorial basado en la colaboración entre los actores sociales que tienen que ver con la práctica del ecoturismo en la Reserva de la Biosfera Sierra La Laguna. 
EL ECOTURISMO COMO BASE PARA EL DESARROLLO TERRITORIAL SOSTENIBLE EN LA RESERVA DE LA BIOSFERA SIERRA LA LAGUNA (REBIOSLA), BAJA CALIFORNIA SUR, MÉXICO

Ismael Rodríguez Villalobos Angélica Montaño Armendáriz Roberto González Sousa

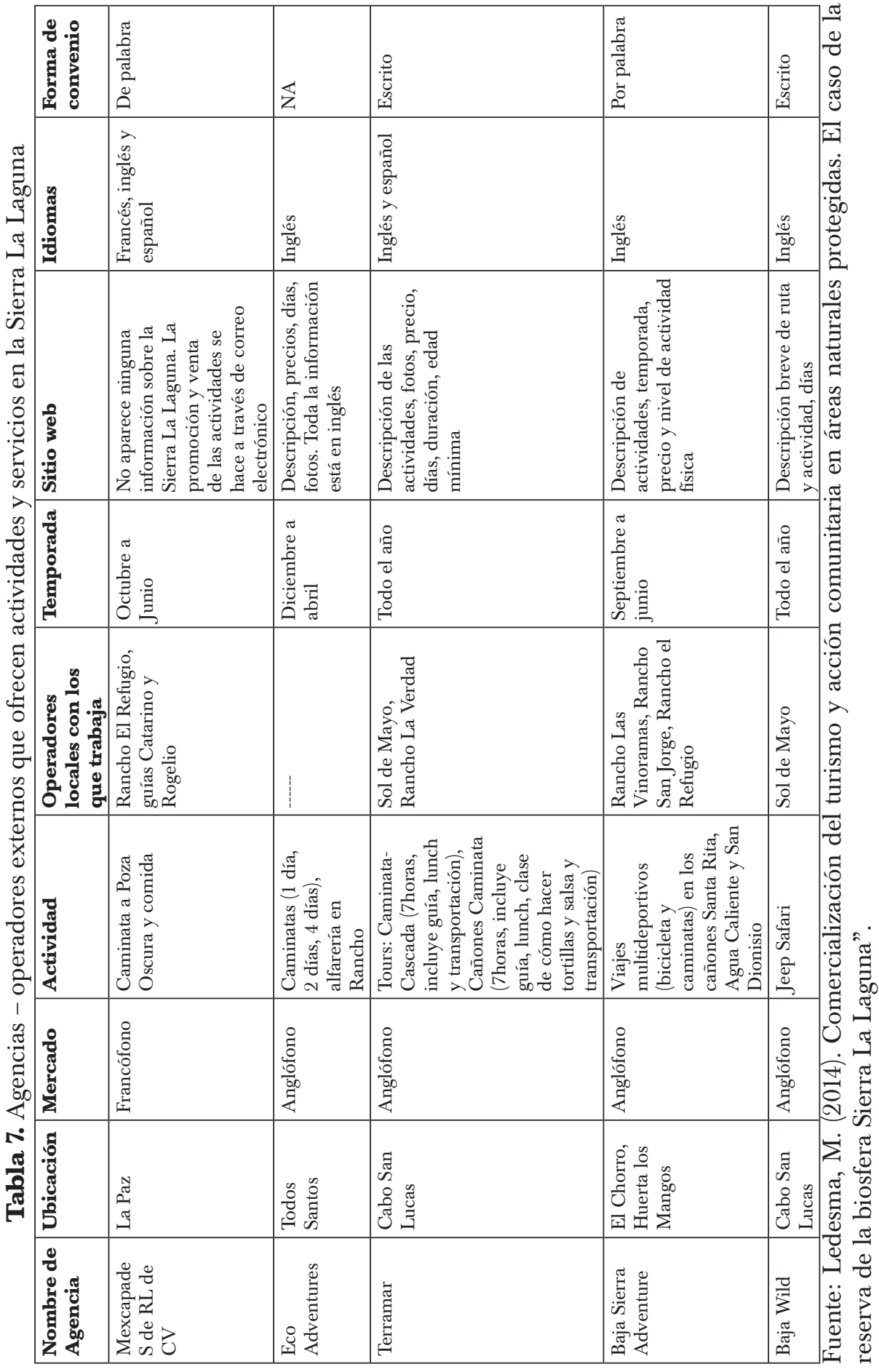




\section{Propuestas para el desarrollo de productos ecoturísticos}

La ejecución de un proyecto ecoturístico que concibe un producto adaptado a las condiciones propias de sus actores locales y de la región, repercutirá en un modelo de desarrollo donde el hombre y la naturaleza se complementan. Por tanto, debe tomar en cuenta los recursos y su manejo sustentable. No es posible obviar en su diseño las estrategias de rentabilidad y marketing, que eviten el fracaso en emprendimientos locales, dejando establecido nítidamente la condición de la sostenibilidad en el territorio y en la localidad, así como la actuación de los diferentes actores locales (Saldivar, 2004)..

El desarrollo sustentable de productos ecoturísticos debe ser capaz de garantizar su sustentabilidad económica, crear empleos y mejorar la calidad de vida de la comunidad local, en tanto resultado de un compromiso que considere el territorio como lugar de solidaridad activa de todos los actores implicados. Ello exige cambios de actitudes y comportamientos de todos los actores de la Reserva y la necesidad de encontrar, desde la misma realidad del desarrollo de las localidades, un enfoque que se corresponda con las exigencias actuales en materia de desarrollo, con la participación de la población local, y dirigido a la formación de un sistema territorial productivo de base turística.

A criterio de los autores, solo aplicando este enfoque se garantiza la conformación de un producto ecoturístico integral en áreas conservadas, a partir de la participación de los actores, con un enfoque territorial sistémico, como forma de representación espacial, y donde se muestren a los sistemas naturales, desde la ocupación y apropiación por los diferentes actores, que contribuyen a su conservación y al desarrollo local.

El procedimiento que se presenta en este informe preliminar de investigación cumple con las características siguientes: es holístico, sistémico, contextualizado y flexible, estratégico y espacial, y responde a las actuales exigencias territoriales en cuanto a la integración, el uso racional de lo que existe, el fomento o potenciación y la rehabilitación, todo ello encaminado al desarrollo local sostenible, a partir del análisis de las posibilidades y potencialidades que pudieran contribuir a conformar y fortalecer un sistema productivo de base turística. Su aplicación se contextualiza en la REBIOSLA, a partir de las particularidades específicas que ella presenta en cuanto a su patrimonio natural e histórico cultural.

Para comprender las relaciones establecidas entre los actores se hace necesario establecer su área de influencia en el territorio de la REBIOSLA, para determinar el comportamiento de los mismos, en cuanto a la práctica del ecoturismo. La misma no es estática, se puede extender o contraer, según la dinámica de las relaciones de los actores y en función de las actividades de conservación y uso público. Esto permitirá determinar el grado de articulación de las relaciones de actores con la práctica del ecoturismo. Es necesario trabajar con indicadores tanto cuantitativos como cualitativos, que no son excluyentes si no complementarios. Así, una parte de ellos tienen la capacidad de medir la evaluación que ha experimentado cada actividad en el tiempo de aplicación, con una escala de valoración para cada uno de los indicadores seleccionados de insatisfactorio, satisfactorio, y óptimo y los criterios de medida expresados en rangos de porciento, número y tendencia.

Los aportes metodológicos, acompañados del procedimiento para su ejecución, tienen como fin el mejoramiento permanente de las relaciones de los actores, con el propósito de desarrollar un sistema productivo territorial de base turística, con 
EL ECOTURISMO COMO BASE PARA EL DESARROLLO TERRITORIAL SOSTENIBLE EN LA RESERVA DE LA BIOSFERA SIERRA LA LAGUNA (REBIOSLA), BAJA CALIFORNIA SUR, MÉXICO
Ismael Rodríguez Villalobos Angélica Montaño Armendáriz Roberto González Sousa

productos ecoturísticos competitivos e integrales, que se conviertan en herramientas de conservación y desarrollo local sostenible, primeramente en las regiones que presentan mayores emprendimientos ecoturísticos (Santiago y Todos Santos) y posteriormente, su generalización a toda la REBIOSLA.

El procedimiento propuesto cuenta con un conjunto de acciones que son necesarias realizar para el desarrollo e implementación del mismo. Estas acciones en una versión resumida son:

$\checkmark \quad$ La declaración explícita y detallada para el territorio de la Reserva de la Biosfera de la Sierra La Laguna, del contenido de las dimensiones ambiental, económica, social, político- institucional y tecnológica que le son esenciales.

$\checkmark \quad$ El diseño y aplicación de instrumentos a los actores implicados y la definición de su rol.

$\checkmark \quad$ La realización de talleres de sensibilización con la utilización de técnicas de trabajo en grupo.

$\checkmark \quad$ Aplicación de instrumentos que midan la implementación y la integración de los actores en la práctica del ecoturismo en el territorio de la REBIOSLA.

$\checkmark \quad$ Monitoreo y valoración de los resultados ambientales, económicos y sociales, obtenidos, en función de la proyección ecoturística en el territorio.

$\checkmark \quad$ Implementación de medidas correctoras y factibilidad del diseño de nuevos emprendimientos ecoturísticos en el territorio.

\section{Conclusiones}

El análisis integral de la Reserva de la Biosfera Sierra La Laguna, y de sus regiones, a partir de una concepción sistémica, soporte teórico del diagnóstico de los diferentes componentes del sistema territorial de la Reserva y de las relaciones establecidas entre los actores principales del área, y premisa necesaria para alcanzar un modelo de desarrollo sostenible del producto ecoturístico, ha tenido en cuenta la vocación territorial, las potencialidades del patrimonio local existentes, la integración de las operaciones turísticas y la normatividad para la operatividad en áreas protegidas.

Se considera que el desarrollo del ecoturismo en la Reserva, pensado desde la sostenibilidad, debe promover la integración de todos los actores que intervienen en el área y su espacio de influencia, sustentado en un adecuado manejo de las relaciones entre ellos, y dirigido a la formación de un sistema territorial basado en la colaboración entre los actores sociales que tienen que ver con el turismo, con una doble finalidad: el cuidado y conservación de los recursos y la creación de un producto competitivo por su calidad y que contribuya al progreso de los actores participantes, a partir de sus propias condiciones y recursos, lo que les sitúa como centro de su propio desarrollo.

En el contexto territorial, el ecoturismo como expresión tangible del conjunto de relaciones debe ser valorado como el núcleo en torno al cual se constituye la cadena productiva del sistema. Por tanto, las estrategias de desarrollo ecoturístico en los territorios deben obedecer al manejo responsable de los recursos naturales y culturales, mediante el establecimiento de lineamientos de ordenamiento que orienten la toma de decisiones hacia el diseño de productos coherentes, desde lo ambiental, lo social y lo económico, lo cual debe apoyarse en el diseño de un plan de marketing para la promoción y un mejor funcionamiento de las actividades ecoturísticas en el territorio. 
La importancia del diseño de productos ecoturísticos coherentes, a partir del adecuado manejo de las relaciones de actores, concuerda con los objetivos de conservar el patrimonio natural e histórico - cultural de la Reserva y de brindar un uso público con calidad, pues de ello dependerá la propia existencia de la actividad ecoturística en este espacio protegido. Ello justifica la necesidad de concebir el desarrollo del sistema productivo territorial de base turística que debe tener como soporte las múltiples interacciones que se producen entre sus componentes o dimensiones, y debe basar su esencia en la apreciación y conservación de la naturaleza y la cultura interactuantes en un mismo espacio.

A criterio de los autores, desde la óptica del desarrollo del sistema territorial, los actores sociales deben reconocerse por su capacidad colectiva para asumir la función de planificación y de gestión ascendente del desarrollo, como una de las principales fuerzas e indicadores del desarrollo de un sistema productivo de base turística. El ecoturismo, como una opción de desarrollo económico, social y ambiental en el territorio de la Reserva, debe estar incluido en los planes de ordenamiento y en las estrategias de utilización de los recursos patrimoniales de la Reserva, en función de un progreso local sostenible como un sistema territorial.

Como aportes de la investigación en desarrollo se señalan la apropiada actualización y adaptación sobre bases científicas del desarrollo del ecoturismo a las condiciones específicas de la REBIOSLA; revelar los elementos que deben conformar las relaciones de actores en el desarrollo de un producto ecoturístico y que sustentan una alternativa de desarrollo territorial sostenible para la Reserva, con mayor énfasis en las regiones Santiago y Todos Santos, donde se localizan la mayor cantidad de emprendimientos locales con esta finalidad; el estudio de las relaciones de actores para la conformación de un sistema productivo de base turística como alternativa de desarrollo territorial sostenible, y alternativa para resolver la contradicción fundamental que se establece entre las relaciones de los diferentes actores del territorio en el desarrollo de un producto ecoturístico sostenible.

\section{Bibliografía}

Castorena, L., Breceda, A. 2003. Diagnóstico social y diseño de estrategia operativa para la Reserva de la Biosfera Sierra La Laguna. Secretaria de Medio Ambiente y Recursos Naturales-Comisión Nacional de Áreas Protegidas y Banco Mundial. México.

Castorena, L., Breceda, A. 2008. Remontando el Cañón de la Zorra. Instituto Sudcaliforniano de Cultura. Gobierno del Estado de BCS.

Ceballos-Lascurain, H. 1998. Ecoturismo, Naturaleza y Desarrollo Sostenible. Editorial Diana. México.

Ceballos-Lascurain, H. 2001. Integrating Biodiversity into the Tourism Sector: Best Practice Guidelines Report submitted to UNEP/UNDP/GEF/BPSP.

64 Chávez de la Peña, J. 1997. Apuntes de ecoturismo. Instituto Politécnico Nacional. México D. F.

Comisión Nacional de Áreas Protegidas (CONANP). 2003. Programa de manejo de la Reserva de la Biosfera Sierra La Laguna. México. Primera edición. México, D. F.

Comisión Nacional de Áreas Protegidas (CONANP). 2011. Estrategia nacional para un desarrollo sustentable del turismo y la recreación en las áreas protegidas de México. Disponible en: http://www. conanp.gob.mx/pdf_publicaciones/TurismoEstrategia.pdf

Dirección de la Reserva de la Biosfera Sierra La Laguna. 2000. Censo de población de la Reserva de la Biosfera Sierra La Laguna, 2000. Baja California Sur. México. 
EL ECOTURISMO COMO BASE PARA EL DESARROLLO TERRITORIAL SOSTENIBLE EN LA RESERVA DE LA BIOSFERA SIERRA LA LAGUNA (REBIOSLA), BAJA CALIFORNIA SUR, MÉXICO
Ismael Rodríguez Villalobos Angélica Montaño Armendáriz Roberto González Sousa

Dirección de la Reserva de la Biosfera Sierra La Laguna. 2016. Base de datos de proyectos de inversión de la Reserva de la Biosfera Sierra La Laguna, 2016. Baja California Sur. México.

Eagles, P., McCool, S. y Haynes, C. 2002. Turismo sostenible en áreas protegidas. Directrices de planificación y gestión. Organización Mundial del Turismo, Programa de las Naciones Unidas para el Medio Ambiente y Unión Mundial para la Naturaleza. Madrid.

Fasio, L., Váquez E. y Ibáñez, R. 2012. Turismo de naturaleza en zonas rurales biodiversas de México: potencialidades y retos. TURyDES, Vol. 5, núm. 12. México. D. F.

Gutiérrez González, M. V. G. 2011. Evaluación del impacto del turismo de naturaleza en San Dionisio, Baja California Sur, México Tesis de Licenciatura en Turismo Alternativo. La Paz, Baja California Sur. México.

Jiménez Martínez, A. de J. 1998. Desarrollo turístico y sustentabilidad: el caso de México, Editorial Miguel A. Porrúa, México, D. F.

Jiménez Martínez, A. de J. 2010. Cadenas hoteleras. Estrategias y territorio en el Caribe mexicano. Universidad del Caribe. México.

Lagunas-Vázques, M., Beltrán Morales, L. F. y Ortega Rubio, Alfredo (editores). 2013. Diagnóstico y análisis de los aspectos sociales y económicos en la reserva de la biosfera Sierra La Laguna, Baja California Sur, México. Centro de Investigaciones Biológicas del Noroeste S.C. (CIBNOR), La Paz, B.C.S., México.

Ledesma Avila, M. 2014. Comercialización del turismo y acción comunitaria en áreas naturales protegidas. El caso de la reserva de la biosfera Sierra La Laguna. Universidad Autónoma de Baja California Sur. México

López Olivares, D. 2014. Los recursos turísticos. Colección Crónica. Ed. Tirant Humanidades. Valencia. España.

Martínez Puche, A. 2001. Las comunidades rurales y le turismo. Algunas consideraciones desde la perspectiva del desarrollo local. Martínez Puche Antonio (coord.). El desarrollo rural/local y el papel de los poderes locales. Nuevas consideraciones sectoriales y sus repercusiones en el territorio valenciano. Publicaciones Universidad de Alicante. 280-313.

Medina, N., Santamarina, J., Salinas Chávez, Eros. 2010. Productos turísticos. Desarrollo y comercialización. La experiencia de Cuba. La Habana. Ed. Balcón. La Habana.

Meza Arce, M. I. (s/f). Los PROCODES una estrategia de conservación para el desarrollo en la Reserva de la Biosfera Isla Guadalupe. Baja California. México.

Organización Mundial del Turismo. 2002. El mercado canadiense del ecoturismo. Informe especial, núm. 15. Sección de Estudios de Mercado y técnicas de Promoción/Sección de Desarrollo Sostenible del Turismo. Madrid.

Pérez, M. 2004. Manual del Turismo Sostenible. Ed. Mundi Prensa, Madrid.

Programa Estatal de Ordenamiento Territorial. Baja California Sur. 2003. Resumen ejecutivo. Coordinadores Ismael Rodriguez y Roberto González. Universidad Autónoma de Baja California Sur/Universidad de La Habana.

Red Mexicana de Ecoturismo. El ecoturismo: Definición, Alcances y Desarrollo en el Mundo. Disponible en: http://www.planeta.com/ecotravel/mexico/red.html. (Consulta: marzo 15, 2009).

Saldivar Valdés, A. 2004. Reseña de estrategia de conservación para el desarrollo. Estrategia de conservación para el desarrollo. Comisión Nacional de Áreas Protegidas. Problemas del Desarrollo. Revista Latinoamericana de Economía. Vol. 35, núm. 137. 225-228. México.

Salinas Chávez, E. 2003. Geografía y Turismo. Aspectos Territoriales del manejo y gestión del Turismo. Ediciones SI-MAR S.A., La Habana, Cuba.

Sectur. 2010. El Turismo Cultural en México. Resumen Ejecutivo del Estudio Estratégico de Viabilidad del Turismo Cultural en México. Disponible en: http://www.sectur.gob.mx/work/ secciones/9246/imagenes/Resumen_Ejecutivo. (Consulta: junio 5, 2011).

Suárez, I., Gutiérrez, A. 2016. Turismo, sociedad y cultura, visiones interdisciplinarias para el desarrollo. Fundación Red Iberoamericana de Ciencia, Naturaleza y Turismo. Valdivia. Chile. 